OPEN ACCESS

Edited by:

Bilge Hilal Cadirci,

Gaziosmanpasa University, Turkey

Reviewed by:

Nils-Kaare Birkeland,

University of Bergen, Norway

Runar Stokke,

University of Bergen, Norway

Julie L. Meyer,

University of Florida, USA

*Correspondence:

Phillip J. Brumm,

C5-6 Technologies Inc., 2905

Parmenter St., Middleton, WI 53562 ,

USA

pbrumm@c56technologies.com

Specialty section:

This article was submitted to

Extreme Microbiology,

a section of the journal

Frontiers in Microbiology

Received: 11 February 2015 Accepted: 22 April 2015

Published: 12 May 2015

Citation:

Brumm PJ, De Maayer P, Mead DA and Cowan DA (2015) Genomic

analysis of six new Geobacillus strains

reveals highly conserved carbohydrate degradation architectures and

strategies. Front. Microbiol. 6:430.

doi: $10.3389 /$ fmicb.2015.00430

\section{Genomic analysis of six new Geobacillus strains reveals highly conserved carbohydrate degradation architectures and strategies}

\author{
Phillip J. Brumm 1,2*, Pieter De Maayer ${ }^{3,4}$, David A. Mead ${ }^{1,2,5}$ and Don A. Cowan ${ }^{3}$ \\ ${ }^{1}$ C5•6 Technologies, Middleton, WI, USA, ${ }^{2}$ Great Lakes Bioenergy Research Center, University of Wisconsin, Madison, WI, \\ USA, ${ }^{3}$ Centre for Microbial Ecology and Genomics, Genomics Research Institute, University of Pretoria, Pretoria, \\ South Africa, ${ }^{4}$ Department of Microbiology and Plant Pathology, University of Pretoria, Pretoria, South Africa, ${ }^{5}$ Lucigen \\ Corporation, Middleton, WI, USA
}

In this work we report the whole genome sequences of six new Geobacillus xylanolytic strains along with the genomic analysis of their capability to degrade carbohydrates. The six sequenced Geobacillus strains described here have a range of GC contents from $43.9 \%$ to $52.5 \%$ and clade with named Geobacillus species throughout the entire genus. We have identified a $\sim 200 \mathrm{~kb}$ unique super-cluster in all six strains, containing five to eight distinct carbohydrate degradation clusters in a single genomic region, a feature not seen in other genera. The Geobacillus strains rely on a small number of secreted enzymes located within distinct clusters for carbohydrate utilization, in contrast to most biomass-degrading organisms which contain numerous secreted enzymes located randomly throughout the genomes. All six strains are able to utilize fructose, arabinose, xylose, mannitol, gluconate, xylan, and $\alpha-1,6$-glucosides. The gene clusters for utilization of these seven substrates have identical organization and the individual proteins have a high percent identity to their homologs. The strains show significant differences in their ability to utilize inositol, sucrose, lactose, $\alpha$-mannosides, $\alpha-1,4$-glucosides and arabinan.

Keywords: xylan, Geobacillus, galactose, arabinan, starch, genome sequencing, biomass, metabolism

\section{Introduction}

Thermophiles have been a source of industrial enzymes for over 30 years (Vieille and Zeikus, 2001; Haki and Rakshit, 2003; de Miguel Bouzas et al., 2006). A range of industrial applications including paper manufacturing, brewing, biomass deconstruction and the production of animal feeds (Dersjant-Li et al., 2001; Tricarico and Dawson, 2005; Valls and Roncero, 2009; Valls et al., 2010) have used thermophilic enzymes for the degradation of xylan. Xylans are the most abundant form of hemicellulose (Saha, 2003). The defining feature of xylans is a backbone of beta-1,4linked xylose residues. While cellulose is a homopolymer of beta-1,4-linked glucose, xylans are heteropolymers containing a range of species-specific modifications to the backbone chain (Saha, 2003). These modifications include the attachment of neutral sugars such as arabinose, galactose, and glucose, attachment of charged sugars such as glucuronic acid, and acetylation, giving rise to unsubstituted xylans, arabinoxylans, glucuronoxylans, and arabinoglucuronoxylans (these will all be collectively called xylan). The result of these modifications is a bewildering diversity in 
the chemical compositions and structures of xylans (recently reviewed in Girio et al., 2010), and the need for a wide range of enzymes and enzyme activities to degrade these structures. As a result, many enzymes active on xylan have been isolated and characterized from a wide range of organisms, especially thermophilic bacteria. Geobacillus stearothermophilus (previously known as Bacillus stearothermophilus, Nazina et al., 2001) is a heavily studied source of many xylandegrading enzymes. Xylan-degrading enzymes characterized from Geobacillus stearothermophilus strain T-6 include two xylanases (Teplitsky et al., 2004; Solomon et al., 2007), an $\alpha$-glucuronidase (Choi et al., 2000), three xylosidases (Bravman et al., 2003; Czizek et al., 2004; Brux et al., 2006), one arabinofuranosidase, and one arabinopyranosidase (Shallom et al., 2002; Salama et al., 2012). Other Geobacillus species have been identified as sources of thermostable xylanase (Gerasimova and Kuisiene, 2012; Liu et al., 2012; Verma and Satyanarayana, 2012; Anand et al., 2013; Bhalla et al., 2014), with all the enzymes showing properties similar to those of the G. stearothermophilus enzyme. A range of other enzymes with potential industrial applications have been identified in Geobacillus species including a-galactosidases (Fridjonsson et al., 1999; Merceron et al., 2012) for use in soy processing, $\beta$-galactosidases (Goodman and Pederson, 1976; Hirata et al., 1984, 1986; Solomon et al., 2013) for use in milk processing, lipases (Jeong et al., 2001; Sinchaikul et al., 2002; Abdul Rahman et al., 2009; Ebrahimpour et al., 2011; Balan et al., 2012) and proteases (Nishiya and Imanaka, 1990; Jang et al., 1992; Hawumba et al., 2002; Chen et al., 2004; Itoi et al., 2006) for use in detergents, and amylases (Sen and Oriel, 1989; Brumm et al., 1991; Narang and Satyanarayana, 2001; Kamasaka et al., 2002; Ferner-Ortner-Bleckmann et al., 2009; Mok et al., 2013; Nasrollahi et al., 2013) for use in corn wet milling, baking and ethanol production.

A $23.55 \mathrm{~kb}$ genomic DNA fragment from Geobacillus stearothermophilus strain T-6 contains the genes for extracellular and intracellular xylanases, $\beta$-xylosidase, and 12 genes involved in transport and metabolism of glucuronic acid (Shulami et al., 1999). The organization of the arabinan utilization genes from this organism, which form a separate cluster contiguous to the xylan utilization cluster, was described later (Shulami et al., 2011). A complete genome sequence for G. stearothermophilus strain T-6 has not been published, resulting in only limited understanding of the organization of xylan and arabinan metabolism within the G. stearothermophilus genome. Without a complete genome, it is also unclear if the genes present in these two clusters represent the complete set of genes needed for pentosan degradation. Without complete genome sequences, it is impossible to determine the genomic context of the individual enzymes described above, and if these individual enzymes are present at the genus, species, or strain level.

Whole genome sequencing is a potent tool for understanding the collection of genes a microorganism utilizes for carbohydrate degradation (Suen et al., 2011; Mead et al., 2012, 2013; Christopherson et al., 2013). To date, only a limited number of complete Geobacillus genomes have been published including G. thermodenitrificans (Feng et al., 2007; Yao et al., 2013), G. kaustophilus (Takami et al., 2004), Geobacillus sp. strain GHH01
(Wiegand et al., 2013), Geobacillus sp. strain JF8 (Shintani et al., 2014), G. thermoglucosidans TNO-09.020 (Zhao et al., 2012), and G. thermoleovorans CCB_US3_UF5 (Muhd Sakaff et al., 2012), and no detailed analysis of the carbohydrate degradation systems of these organisms have been published. Our group has isolated six novel xylanolytic Geobacillus strains as part of an effort to identify new, high specific activity thermophilic enzymes. The genomes of all six strains have been determined, with five of the six genome sequences deposited in GenBank, and the sixth available via the JGI genome portal. Using these genome resources, the carbohydrate degradation clusters in these six strains were identified and compared. The results of this analysis revealed that both the organization and the individual genes of carbohydrate metabolism are highly conserved throughout the genus. In addition, many of these carbohydrate degradation clusters reside in a single, 200-kb conserved genome region.

\section{Materials and Methods}

The azurine cross-linked-labeled (AZCL) polysaccharide AZCLArabinoxylan (AZCL-AX) and was obtained from Megazyme International (Wicklow, Ireland). 4-Methylumbelliferyl$\beta$-D-cellobioside (MUC) and 4-methylumbelliferyl- $\beta$-Dxylopyranoside (MUX), were obtained from Research Products International Corp. (Mt. Prospect, IL, USA). CelLytic IIB reagent, birchwood xylan, arabinogalactan from larch wood (Fluka) and 4-methylumbelliferyl- $\alpha$-D-arabinofuranoside (MUA) were purchased from Sigma-Aldrich (St. Louis, MO, USA). Xylo-oligosaccharides were obtained from Cascade Analytical Reagents and Biochemicals (Corvallis, OR, USA). All other chemicals were of analytical grade.

Geobacillus strains were isolated from environmental samples (Table 1) on YTP-2 agar (contains (per liter) $2.0 \mathrm{~g}$ yeast extract, $2.0 \mathrm{~g}$ tryptone, $2.0 \mathrm{~g}$ sodium pyruvate, $1.0 \mathrm{~g} \mathrm{KCl}, 2.0 \mathrm{~g} \mathrm{KNO} 3$, $2.0 \mathrm{~g} \mathrm{Na}_{2} \mathrm{HPO}_{4} .7 \mathrm{H}_{2} \mathrm{O}, 0.1 \mathrm{~g} \mathrm{MgSO}_{4}, 0.03 \mathrm{~g} \mathrm{CaCl}_{2}, 8.0 \mathrm{~g}$ agar, and $2.0 \mathrm{ml}$ clarified tomato juice) at $70^{\circ} \mathrm{C}$ as described previously (Mead et al., 2012). For preparation of genomic DNA, 1 liter cultures of Geobacillus isolates were grown from a single colony in YTP-2 medium at $70^{\circ} \mathrm{C}$ in flasks agitated at $200 \mathrm{rpm}$ for $18 \mathrm{~h}$ and collected by centrifugation. The cell concentrate was lysed using a combination of SDS and proteinase $\mathrm{K}$, and genomic DNA was isolated using a phenol/chloroform extraction (Sambrook et al., 1989). The genomic DNA was precipitated, and treated with RNase to remove residual contaminating RNA.

Cultures for enzyme assays were grown in $1.0 \mathrm{ml}$ of YT2 medium (contains (per liter) $2.0 \mathrm{~g}$ yeast extract, $2.0 \mathrm{~g}$ tryptone, $2.0 \mathrm{~g}$ carbohydrate substrate, $1.0 \mathrm{~g} \mathrm{KCl}, 2.0 \mathrm{~g} \mathrm{KNO}_{3}, 2.0 \mathrm{~g}$ $\mathrm{Na}_{2} \mathrm{HPO}_{4} .7 \mathrm{H}_{2} \mathrm{O}, 0.1 \mathrm{~g} \mathrm{MgSO}_{4}, 0.03 \mathrm{~g} \mathrm{CaCl}, 8.0 \mathrm{~g}$ agar, and $2.0 \mathrm{ml}$ clarified tomato juice). Cultures were grown from single colonies at $70^{\circ} \mathrm{C}$ in $2.0 \mathrm{ml}$ screw-cap vials for $72 \mathrm{~h}$ at $1000 \mathrm{rpm}$ in a Thermomixer R (Eppendorf, Hamburg, Germany). Cells were recovered by centrifugation, and the cell pellets were lysed by treatment with $0.1 \mathrm{ml}$ of CelLytic IIB reagent. Qualitative endoactivities of supernatant and lysate samples were determined in $0.50 \mathrm{ml}$ of $50 \mathrm{mM}$ acetate buffer, $\mathrm{pH} 5.8$, containing $0.2 \%$ AZCL insoluble substrates and $50 \mu \mathrm{l}$ of supernatant or $10 \mu \mathrm{l}$ of clarified lysate. Assays were performed overnight at $70^{\circ} \mathrm{C}$, 
TABLE 1 | Geobacillus genomes sequenced in this work.

\begin{tabular}{|c|c|c|c|c|}
\hline & MC52, MC61, YS93 & $1 \mathrm{MC} 16$ & $56 \mathrm{~T} 2$ & $56 \mathrm{T3}$ \\
\hline Source & Obsidian hot spring WY, USA & Grass compost WI, USA & Double hot springs NV, USA & Sandy's spring west NV, USA \\
\hline Latitude & 44.376262 & 43.111566 & 41.051289 & 40.651893 \\
\hline Longitude & -110.690383 & -89.518892 & -119.028790 & -119.376659 \\
\hline Temperature & $79^{\circ} \mathrm{C}$ & $60^{\circ} \mathrm{C}$ & $79.6^{\circ} \mathrm{C}$ & $80^{\circ} \mathrm{C}$ \\
\hline $\mathrm{pH}$ & 6.7 & unknown & 8.0 & 7.4 \\
\hline
\end{tabular}

with shaking at $1000 \mathrm{rpm}$ in a Thermomixer R. Tubes were clarified by centrifugation, and absorbance values at $600 \mathrm{~nm}$ were determined using a Bio-Tek ELx800 plate reader. The exoactivities of supernatant and lysate samples were determined by spotting $5.0 \mu \mathrm{l}$ of clarified lysate directly on agar plates containing $10 \mathrm{mM} 4$-methylumbelliferyl substrate. Plates were incubated in a $70^{\circ} \mathrm{C}$ incubator for $2 \mathrm{~h}$; after incubation, the plates were examined using a hand-held UV lamp and compared with negative and positive controls. Duplicate cultures were used for all assay experiments.

The genomes of six Geobacillus isolates were sequenced at the Joint Genome Institute (JGI) using Sanger sequencing with a combination of $6 \mathrm{~kb}$ and $34 \mathrm{~kb}$ DNA libraries and 454 FLX pyrosequencing done to a depth of $20 \times$ coverage; Solexa sequencing data was used to polish the assemblies. All general aspects of library construction and sequencing performed at the JGI can be found at their website. The Phred/Phrap/Consed software package (Lee and Vega, 2004; Machado et al., 2011) was used to assemble 6-kb and fosmid libraries. Genes were identified using Prodigal (Hyatt et al., 2010) as part of the Oak Ridge National Laboratory genome annotation pipeline, followed by a round of manual curation using the JGI GenePRIMP pipeline (Pati et al., 2010). The predicted CDSs were translated and used to search the National Center for Biotechnology Information (NCBI) non-redundant protein database, UniProt, TIGRFam, Pfam, PRIAM, KEGG, COG, and InterPro databases. These data sources were combined to assert a product description for each predicted protein. Non-coding genes and miscellaneous features were predicted using tRNAscan-SE (Lowe and Eddy, 1997), RNAMMer (Lagesen et al., 2007), Rfam (Griffiths-Jones et al., 2003), TMHMM (Chen et al., 2003), and signalP (Krogh et al., 2001). The Geobacillus cultures are available from the Bacillus Genetics Stock Center (BGSC) at Ohio State University; all genome sequences can be accessed online (Table 1).

The phylogeny of the novel Geobacillus strains was determined using the 16S rRNA gene sequences of the six sequenced strains, as well as those of the type strains of all validly described Geobacillus spp. The 16S rRNA gene sequences were aligned using MUSCLE (Edgar, 2004), pairwise distances were estimated using the Maximum Composite Likelihood (MCL) approach, and initial trees for heuristic search were obtained automatically by applying the Neighbour-Joining method in MEGA 5 (Tamura et al., 2011). The alignment and heuristic trees were then used to infer the phylogeny using the Maximum Likelihood method based on the Tamura-Nei (Tamura and Nei, 1993).
Carbohydrate utilization enzymes were identified from UniProt (Apweiler et al., 2004; Consortium, 2013, 2014), and BLASTp analysis (Cameron et al., 2004) was used to identify orthologs in the genomes. Neighborhood analysis was performed using IMG tools (Markowitz et al., 2012) to determine clusters and manually curate the electronic annotations.

\section{Results}

As part of a project to identify new thermophilic enzymes that degrade biomass, microbial cultures from hot springs and composts were isolated and biochemically screened to identify novel, aerobic, biomass-degrading thermophiles. Aerobic enrichments were performed at $70^{\circ} \mathrm{C}$, and the vast majority of the 100 isolates were Geobacillus or Thermus species. Six of these Geobacillus isolates were selected for additional characterization based on the ability of colonies to hydrolyze MUX or MUC incorporated into agar plates. Five of these isolates were from hot springs in the United States (Yellowstone National Park and Nevada) and one was from a grass compost sample collected in Middleton WI (Table 1).

To determine if these isolates produced xylan degrading enzymes, the six selected cultures (designated C56-YS93 (YS93), G11MC16 (1MC16), Y412MC52 (MC52), Y412MC61 (MC61), C56-56T2 (56T2), and C56-T3 (56T3) were grown in $1.0 \mathrm{ml}$ cultures of YT2 media containing one of six carbohydrate substrates (pyruvate, glucose, xylose, arabinose, xylo-oligosaccharides and arabinogalactan) and assayed qualitatively for the production and activity of extracellular xylanase and intracellular $\beta$-xylosidase as described in Materials and Methods. All six strains produced extracellular xylanase when grown on either xylose or pyruvate (Table 2). In addition, extracellular xylanase was produced by at least three of the cultures when grown on arabinose, arabinogalactan or xylooligosaccharides. None of the six strains produced extracellular xylanase when grown on glucose, in agreement with reports of catabolite repression of $G$. stearothermophilus extracellular xylanase production (Cho and Choi, 1999). Intracellular $\beta$ xylosidase was produced by all six strains when grown on xylose while none of the strains produced intracellular $\beta$-xylosidase when grown on pyruvate or glucose. Only one strain (YS93) produced intracellular $\beta$-xylosidase when grown on arabinose, arabinogalactan and xylo-oligosaccharides. The results of the extracellular and intracellular assays confirmed that all six strains possess the ability to degrade xylan. 
TABLE 2 | Enzymatic activities of Geobacillus strains grown on various carbohydrate substrates.

\begin{tabular}{|c|c|c|c|c|c|c|}
\hline Strain & Pyruvate & Xylose & Glucose & Arabinose & $\mathbf{x O}$ & $A^{b} G^{b}$ \\
\hline \multicolumn{7}{|c|}{ EXTRACELLULAR ENZYMATIC ACTIVITY } \\
\hline YS93 & xylanase & xylanase & n.d. & xylanase & xylanase & xylanase \\
\hline $1 \mathrm{MC} 16$ & xylanase & xylanase & n.d. & xylanase & xylanase & n.d. \\
\hline MC52 & xylanase & xylanase & n.d. & n.d. & xylanase & xylanase arabinase \\
\hline MC61 & xylanase & xylanase & n.d. & n.d. & xylanase & xylanase arabinase \\
\hline $56 \mathrm{~T} 2$ & xylanase & xylanase & n.d. & xylanase & n.d. & xylanase \\
\hline $56 \mathrm{T3}$ & xylanase & xylanase & n.d. & n.d. & n.d. & n.d. \\
\hline \multicolumn{7}{|c|}{ INTRACELLULAR ENZYMATIC ACTIVITY } \\
\hline YS93 & n.d. & xylosidase & n.d. & xylosidase & xylosidase & xylosidase \\
\hline 1MC16 & n.d. & xylosidase & n.d. & n.d. & n.d. & n.d. \\
\hline MC61 & arabinosidase & xylosidase & n.d. & n.d. & xylosidase & arabinosidase \\
\hline MC52 & arabinosidase & xylosidase & n.d. & n.d. & xylosidase & arabinosidase \\
\hline 56T2 & n.d. & xylosidase & n.d. & n.d. & n.d. & n.d. \\
\hline 56T3 & n.d. & xylosidase & n.d. & n.d. & n.d. & n.d. \\
\hline YS93 & n.d. & xylosidase & n.d. & xylosidase & xylosidase & xylosidase \\
\hline
\end{tabular}

Geobacillus strains grown and assayed as described in Methods.

${ }^{a} \mathrm{XO}$, xylo-oligosaccharides.

${ }^{b} A G$, arabinogalactan.

n.d. - none detected.

Based on the positive results obtained in the enzyme screening experiments, the six strains were submitted for sequencing by the JGI of the Department of Energy. Genome sequencing yielded five closed genomes with one isolate, $1 \mathrm{MC16}$, left as a permanent draft genome containing 31 contigs (Table 3). The genomes are all of similar size, ranging from 3.5 to 4.0 megabases. Plasmid content varies from none in 56T3, one in MC52 and MC61, and two in strains YS93 and 56T2. The presence of plasmids in $1 \mathrm{MC} 16$ could not be confirmed from the assembled contigs. The genomes display significantly different $\mathrm{G}+\mathrm{C}$ contents. YS93 has a mean genomic $\mathrm{G}+\mathrm{C}$ content of $43.9 \%, 1 \mathrm{MC} 16$ has an intermediate value of $48.8 \% \mathrm{G}+\mathrm{C}$, and MC52, MC61, 56T2, and $56 \mathrm{~T} 3$ have significantly higher values of $52.3-52.5 \% \mathrm{G}+\mathrm{C}$ (Table 3).

A phylogenetic tree of $16 \mathrm{~S}$ rRNA gene sequences was constructed using the Maximum Likelihood method based on the Tamura-Nei model (Tamura and Nei, 1993) to determine the phylogenetic positions of the novel strains. The resulting tree (Figure 1) shows YS93 clades with G. thermoglucosidasius, $1 \mathrm{MC} 16$ clade with $G$. thermodenitrificans, MC52, MC61, and 56T3 clade with G. stearothermophilus and G. thermocatenulatus, and 56T2 may represent a novel species of Geobacillus. To confirm the assignments obtained with 16S rRNA gene sequences, pairwise average nucleotide identity values were calculated for the six strains against all draft, permanent draft, and finished Geobacillus genomes in the IMG database. Average nucleotide identity values (ANI) (Kim et al., 2014) were calculated using software developed for the IMG (Markowitz et al., 2006, 2014). The results (Table 4) confirm the classification of the strains obtained using 16S rRNA gene sequences. YS93 clades with other G. thermoglucosidasius strains (pink), 1MC16 clades with G. thermodenitrificans strains (blue), 12MC52, $12 \mathrm{MC} 61$, and 56T3 clade together in what appears to be a new species (yellow), and 56T2 appears to clade only with itself (gray).

\section{Identification of Metabolic Clusters}

The six genomes were searched for the location of orthologs of the xylan cluster described in G. stearothermophilus T-6. Surprisingly, in all six strains the xylan utilization cluster is located in a similar, highly conserved region of the Geobacillus genomes (Figure 2). In all six strains, this genome region contains clusters for the utilization of xylan as well as fructose, cellobiose, gluconate, and mannitol utilization clusters. In five of the six strains, clusters for the utilization of arabinan, arabinose, and ribose are also present in this region. Inositol and $\alpha$-mannoside utilization clusters are present this region in one strain. In addition to carbohydrate utilization clusters, all six strains possess a 16-gene biosynthesis cobalamin cluster and a 4-gene nitrite reductase cluster. Five of the six strains contain a 13-gene urea utilization cluster and a 4-gene nitrate reductase cluster. This large super-cluster of metabolic clusters, conserved at the genus level, appears to be a unique feature of the Geobacillus. Carbohydrate utilization clusters found in this $\sim 200 \mathrm{~kb}$ region of the genomes will be described first, proceeding in the direction of transcription. Following these descriptions, carbohydrate utilization clusters not found in the $\sim 200 \mathrm{~kb}$ region will be described.

\section{Carbohydrate Clusters Found in the $\sim 200$ $\mathrm{Kb}$ Region of the Sequenced Geobacillus Strains}

\section{Mannitol Metabolism}

In all six strains, orthologous clusters code for three-component phosphotransferase system (PTS) that uses phosphoenolpyruvate to transport the sugar into the cell and phosphorylate it, generating intracellular mannitol-1-phosphate. A MtlR family 
TABLE 3 | Geobacillus sequencing results.

\begin{tabular}{|c|c|c|c|c|c|}
\hline Geobacillus species & Genome size & Genome contigs & Plasmids & GC content & GenBank ID \\
\hline YS93 & $3,993,793$ & 1 & 2 & 43.9 & NC_015660 \\
\hline $1 \mathrm{MC} 16$ & $3,545,187$ & 31 & n.d. & 48.8 & ABVH01000001-ABVH01000031 \\
\hline MC52 & $3,673,940$ & 1 & 1 & 52.3 & NC_014915 \\
\hline MC61 & $3,667,901$ & 1 & 1 & 52.3 & NC_013411 \\
\hline 56T2 & $3,545,944$ & 1 & 2 & 52.4 & $\mathrm{NA}^{*}$ \\
\hline 56T3 & $3,650,813$ & 1 & 0 & 52.5 & NC_014206 \\
\hline
\end{tabular}

Geobacillus strains isolated and sequenced as described in Methods. "Genome available at http://gp-next.jgi-psf.org:1090/GeospC56T2/GeospC56T2.info.html.

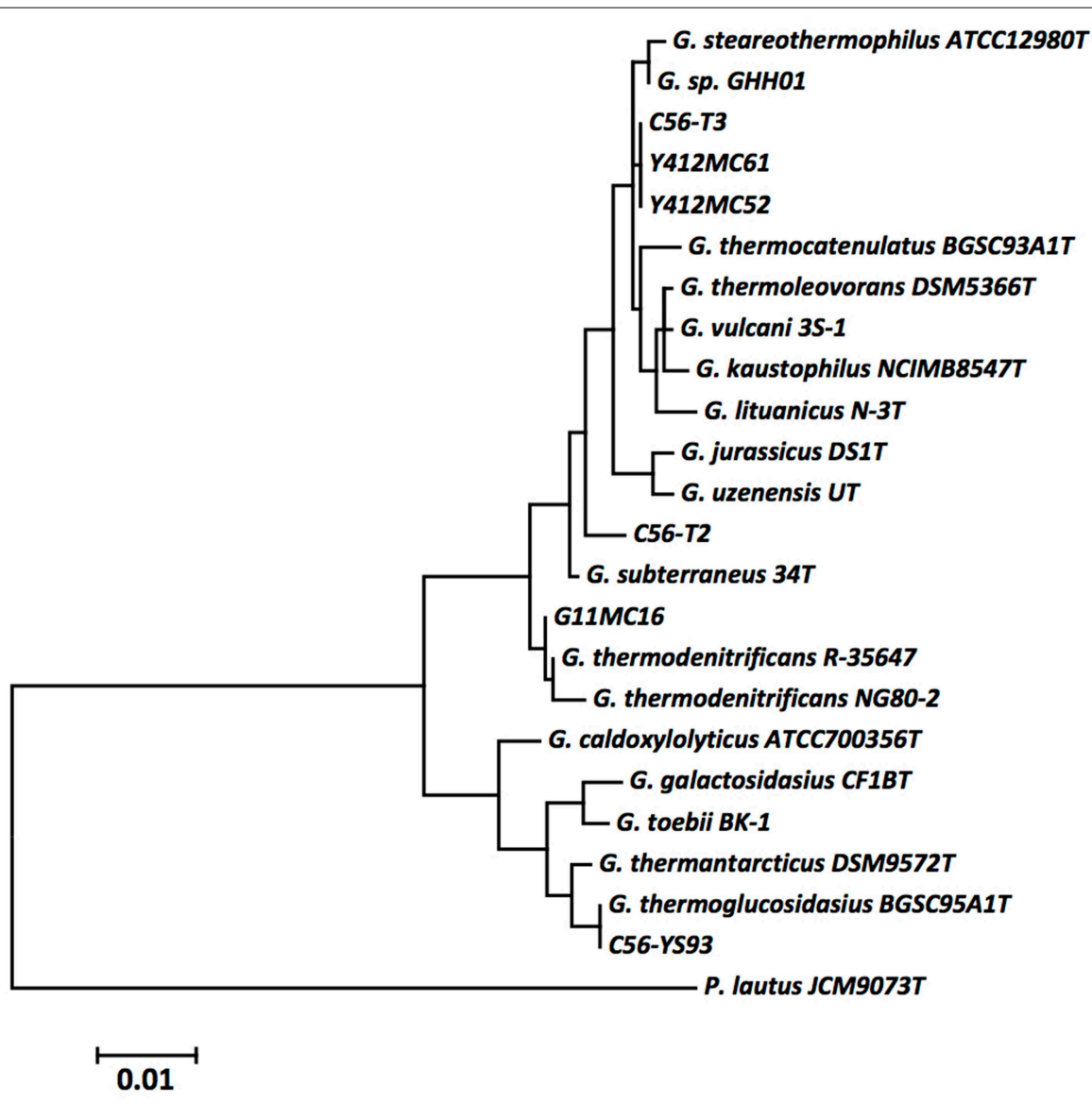

FIGURE 1 | The evolutionary history was inferred by using the Maximum Likelihood method based on the Tamura-Nei model (Tamura and Nei, 1993). The tree with the highest log likelihood $(-3118.4467)$ is shown. Initial tree(s) for the heuristic search were obtained automatically by applying Neighbor-Join and BioNJ algorithms to a matrix of pairwise distances estimated using the Maximum Composite Likelihood (MCL) approach, and then selecting the topology with superior log likelihood value. The tree is drawn to scale, with branch lengths measured in the number of substitutions per site. The analysis involved 24 nucleotide sequences. All positions containing gaps and missing data were eliminated. There were a total of 1260 positions in the final dataset. Evolutionary analyses were conducted in MEGA5
(Tamura et al., 2011). The type strains of all validly described species are included ( $\mathrm{NCBI}$ accession numbers): G. caldoxylolyticus ATCC700356 $^{\top}$ (AF067651), G. galactosidasius CF1B ${ }^{\top}$ (AM408559), G. jurassicus DS1 ${ }^{\top}$ (FN428697), G. kaustophilus NCIMB8547 ${ }^{\top}$ (X60618), G. lituanicus N-3 ${ }^{\top}$ (AY044055), G. stearothermophilus R-35646 ${ }^{\top}$ (FN428694), G. subterraneus $34^{\top}$ (AF276306), G. thermantarcticus

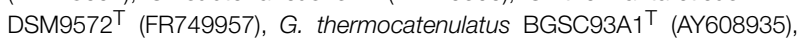
G. thermodenitrificans R-35647 ${ }^{\top}$ (FN538993), G. thermoglucosidasius

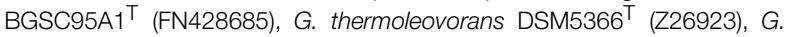
toebii BK-1 $1^{\top}$ (FN428690), G. uzenensis $U^{\top}$ (AF276304), and G. vulcani 3S-1 ${ }^{\top}$ (AJ293805). The 16S rRNA sequence of Paenibacillus lautus $\mathrm{JCM} 073^{\top}$ (AB073188) was used to root the tree. transcriptional regulator controls mannitol uptake in all six strains. The six mannitol utilization clusters also contain a gene coding for mannitol-1-phosphate 5-dehydrogenase, which converts the mannitol-1-phosphate to fructose-1-phosphate. Similar transport and metabolism clusters are used for fructose, cellobiose and sucrose metabolism. 
TABLE 4 | Geobacillus average nucleotide identity (ANI) results.

\begin{tabular}{|c|c|c|c|c|c|c|}
\hline Genome 2 & YS93 & $1 \mathrm{MC16}$ & MC52 & MC61 & $56 \mathrm{~T} 2$ & $56 \mathrm{T3}$ \\
\hline G. caldoxylosilyticus CIC9 & 83.68 & 75.95 & 76.13 & 76.13 & 75.82 & 75.97 \\
\hline G. caldoxylosilyticus NBRC 107762 & 83.66 & 76.46 & 76.01 & 76.00 & 76.15 & 75.89 \\
\hline G. kaustophilus GBlys & 75.92 & 84.20 & 96.60 & 96.61 & 85.87 & 96.65 \\
\hline G. kaustophilus HTA426 & 75.88 & 83.96 & 96.73 & 96.73 & 85.66 & 96.84 \\
\hline G. kaustophilus NBRC 102445 & 75.91 & 84.21 & 96.44 & 96.44 & 85.68 & 96.57 \\
\hline G. sp. A8 & 75.83 & 84.05 & 96.72 & 96.72 & 85.62 & 96.65 \\
\hline G. sp. C56-T2 & 75.40 & 84.00 & 85.32 & 85.39 & 100.00 & 85.35 \\
\hline G. sp. C56-T3 & 75.66 & 83.79 & 98.33 & 98.33 & 85.34 & 100.00 \\
\hline G. sp. Y412MC52 & 75.75 & 83.77 & 100.00 & 100.00 & 85.30 & 98.32 \\
\hline G. sp. Y412MC61 & 75.71 & 83.83 & 100.00 & 100.00 & 85.36 & 98.32 \\
\hline G. sp. CAMR12739 & 75.57 & 83.70 & 97.63 & 97.63 & 85.12 & 97.29 \\
\hline G. sp. CAMR5420 & 75.97 & 83.91 & 96.14 & 96.13 & 85.39 & 96.30 \\
\hline G. sp. FW23 & 75.79 & 84.05 & 96.69 & 96.70 & 85.60 & 96.71 \\
\hline G. sp. GHH01 & 76.00 & 83.85 & 96.46 & 96.48 & 85.44 & 96.55 \\
\hline G. sp. JF8 & 75.68 & 85.60 & 85.56 & 85.55 & 83.69 & 85.42 \\
\hline G. sp. MAS1 & 75.79 & 84.03 & 96.90 & 96.90 & 85.59 & 96.87 \\
\hline G. sp. WCH70 & 86.75 & 75.48 & 75.62 & 75.81 & 75.93 & 75.42 \\
\hline G. sp. WSUCF1 & 76.33 & 83.78 & 96.20 & 96.20 & 85.29 & 96.31 \\
\hline G. stearothermophilus 22 & 76.04 & 84.25 & 89.57 & 89.57 & 84.92 & 89.53 \\
\hline G. stearothermophilus NUB3621 & 83.85 & 76.22 & 76.25 & 76.16 & 75.93 & 76.21 \\
\hline G. stearothermophilus X1 & 71.13 & 70.23 & 69.81 & 69.80 & 69.89 & 70.03 \\
\hline G. subterraneus PSS2 & 75.61 & 83.55 & 85.37 & 85.36 & 97.58 & 85.37 \\
\hline G. thermocatenulatus GS-1 & 75.47 & 83.36 & 94.66 & 94.66 & 84.84 & 94.88 \\
\hline G. sp. G11MC16 & 75.71 & 100.00 & 83.81 & 83.88 & 84.01 & 83.82 \\
\hline G. thermodenitrificans DSM 465 & 75.54 & 99.41 & 83.66 & 83.65 & 83.78 & 83.65 \\
\hline G. thermodenitrificans NG80-2 & 75.88 & 99.46 & 83.70 & 83.77 & 83.98 & 83.74 \\
\hline G. thermoglucosidasius C56-YS93 & 100.00 & 75.63 & 75.76 & 75.77 & 75.41 & 75.65 \\
\hline G. thermoglucosidans YU & 99.35 & 75.53 & 75.50 & 75.72 & 75.52 & 75.53 \\
\hline G. sp. Y4.1MC1 & 99.34 & 75.72 & 75.59 & 75.73 & 75.44 & 75.50 \\
\hline G. thermoglucosidasius GT20 & 99.35 & 75.56 & 75.65 & 75.66 & 75.54 & 75.73 \\
\hline G. thermoglucosidasius M10EXG & 99.36 & 75.44 & 75.53 & 75.54 & 75.20 & 75.48 \\
\hline G. thermoglucosidasius NBRC 107763 & 99.36 & 75.80 & 75.72 & 75.72 & 75.81 & 75.66 \\
\hline G. thermoleovorans B23 & 75.84 & 84.09 & 96.71 & 96.71 & 85.53 & 96.72 \\
\hline G. thermoleovorans CCB_US3_UF5 & 75.74 & 84.17 & 96.72 & 96.74 & 85.68 & 96.65 \\
\hline G. vulcani PSS1 & 75.47 & 83.98 & 91.27 & 91.26 & 88.71 & 91.23 \\
\hline
\end{tabular}

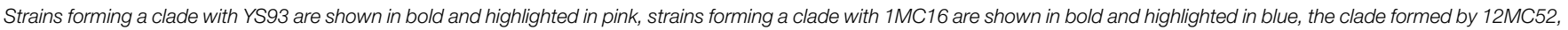
$12 M C 61$, and 56T3 is shown in bold and highlighted in yellow, and 56T2 is highlighted in gray.

\section{Gluconate Metabolism}

All six strains possess an orthologous cluster for gluconate utilization similar to the GntU, GntK, and GntR cluster found in E. coli (Tong et al., 1996). Unlike the B. subtilis gluconate utilization cluster (Reizer et al., 1991), the Geobacillus cluster does not include a GntZ gene coding for 6-phosphogluconate dehydrogenase. The GntZ gene is present in all six strains, located randomly throughout the genomes.

\section{$\alpha$-Mannosides and Inositol-phosphate Utilization}

Only one of the six strains, $1 \mathrm{MC} 16$, possesses the ability to utilize either inositol-phosphates or $\alpha$-mannosides. The two clusters are located upstream of the gluconate cluster, where the other five Geobacillus genomes contain a 13-gene urease/urea utilization cluster. The mannoside utilization cluster has a 3-component $\mathrm{ABC}$ transporter system and an intracellular $\alpha$-mannosidase, all under the control of a GntR family transcriptional regulator. Orthologous mannosidase clusters are present in the genomes of G. thermodenitrificans DSM 465 and G. thermodenitrificans NG80-2 (Feng et al., 2007), and the individual genes of these two strains are $99-100 \%$ identical to their 1MC16 gene counterparts.

The inositol-phosphate utilization cluster (Table 5) has two separate parts. The first is a five-gene cluster containing a 3component $\mathrm{ABC}$ transporter system, inositol 2-dehydrogenase, and an oxidoreductase domain protein. Following this is an inositol metabolic gene cluster of iolG, iolD, iolE, iolB, iolC, and iolA, all under the control of a LacI family transcriptional regulator. Identical inositol-phosphate utilization 


\begin{tabular}{|c|c|c|c|c|c|c|c|c|c|c|c|c|c|}
\hline & Cob & $\mathrm{NO}_{3}$ & Fruc & Cell & $\mathrm{NO}_{2}$ & Xyn & Ara & Pep & Urea & Inos & $\alpha$ Man & Glen & Mtl \\
\hline MC52 & $\Leftarrow$ & $\Rightarrow$ & $\Leftarrow$ & $\Leftarrow$ & $\Leftarrow$ & $\Leftarrow$ & $\Leftarrow$ & $\Leftarrow$ & $\Leftarrow$ & & & $\Leftarrow$ & $\Leftarrow$ \\
\hline MC61 & $\Leftarrow$ & $\Rightarrow$ & $\Leftarrow$ & $\Leftarrow$ & $\Leftarrow$ & $\Leftarrow$ & $\Leftarrow$ & $\Leftarrow$ & $\Leftarrow$ & & & $\Leftarrow$ & $\Leftarrow$ \\
\hline $56 \mathrm{~T} 2$ & $\Leftarrow$ & & $\Leftarrow$ & $\Leftarrow$ & $\Leftarrow$ & $\Leftarrow$ & $\Leftarrow$ & & $\Leftarrow$ & & & $\Leftarrow$ & $\Leftarrow$ \\
\hline YS93 & $\Leftarrow$ & $\Rightarrow$ & $\Leftarrow$ & $\Leftarrow$ & $\Leftarrow$ & $\Leftarrow$ & & $\Leftarrow$ & $\Leftarrow$ & & & $\Leftarrow$ & $\Leftarrow$ \\
\hline $56 \mathrm{T3}$ & $\Leftarrow$ & $\Rightarrow$ & $\Leftarrow$ & $\Leftarrow$ & $\Leftarrow$ & $\Leftarrow$ & $\Leftarrow$ & & $\Leftarrow$ & & & $\Leftarrow$ & $\Leftarrow$ \\
\hline $1 \mathrm{MC16}$ & $\Leftarrow$ & $\Rightarrow$ & $\Leftarrow$ & $\Leftarrow$ & $\Leftarrow$ & $\Leftarrow$ & $\Leftarrow$ & & & $\Leftarrow$ & $\Leftarrow$ & $\Leftarrow$ & $\Leftarrow$ \\
\hline
\end{tabular}

FIGURE 2 | Diagram of major functional clusters found in the conserved regions; carbohydrate utilization clusters are shown in red, non-carbohydrate clusters in blue. Cob, cobalamin biosynthetic cluster, $\mathrm{NO}_{3}$, nitrate reductase cluster; Fruc, fructose utilization cluster; Cell, cellobiose utilization cluster; $\mathrm{NO}_{3}$, nitrite reductase cluster; Xyn, xylose and xylan utilization cluster; Ara, arabinose and arabinan utilization cluster, and ribose transporter cluster: Pep, peptide utilization cluster;
Urea, urease and urea utilization cluster, Inos, inositol-phosphate utilization cluster; aMan, a-mannoside utilization cluster; GLcn gluconate utilization cluster; Mtl, mannitol utilization cluster. The gene sequence values for the corresponding genomes regions are (start-end): MC61, 2635441-2855821; MC52, 1775380-1995757; 56T2, 1737107-1912324; 56T3, 1646809-1858633; YS93, 2080803-2255158; 1MC16, contig ABVH01000004 28446-229812.
TABLE 5 | 1MC16 Inositol-phosphate metabolic cluster.

\begin{tabular}{lc}
\hline Annotation & Gene \\
\hline Inositol 2-dehydrogenase, IolG & 1528 \\
Oxidoreductase domain protein, lolG & 1530 \\
ABC transporter-related protein & 1531 \\
ABC-type transport systems, permease & 1532 \\
ABC-type sugar transport system, periplasmic component & 1533 \\
Transcriptional regulator, Lacl family & 1534 \\
myo-Inositol 2-dehydrogenase, lolG & 1535 \\
Trihydroxycyclohexane-1,2-dione hydrolase, loID & 1536 \\
Inosose dehydratase, lolE & 1537 \\
5-Deoxy-glucuronate isomerase, lolB & 1538 \\
5-Dehydro-2-deoxygluconokinase, lolC & 1539 \\
methylmalonate-semialdehyde dehydrogenase, lolA & 1540 \\
Fructose 1,6-bisphosphate aldolase, lolJ & 1541 \\
\hline
\end{tabular}

clusters are present in G. thermodenitrificans DSM 465 and G. thermodenitrificans NG80-2. Other Geobacillus species possess similar clusters, but are organized with the three-genes of the $\mathrm{ABC}$ transporter following the genes for iolG (Yoshida et al., 2012) and with an additional protein, IolI, 2-keto-myo-inositol isomerase (Figure 3).

\section{Arabinose and Arabinan Metabolism}

Unlike xylan utilization, arabinose and arabinan utilization capability is strongly strain dependent (Table 6). None of the strains possesses the complete arabinan cluster present in G. stearothermophilus T-6 (Shulami et al., 2011). Strain YS93 possesses none of the enzymes required for uptake and metabolism of either arabinose or arabinan. Strain 56T2 possesses the genes for metabolism of arabinose (genes 7-10 and 22-27) but none of the dedicated transporter systems. This suggests that the organism can utilize arabinose in arabinoxylan oligosaccharides that was transported into the cell by xylan transporters, but not extracellular arabinose or arabinan. The arabinose utilization cluster of strains MC52 and MC61 are most similar to the reported T-6 arabinan cluster, lacking only one of the two transporter clusters found in T-6 (genes 1-6). This suggests that these two organisms can utilize the full range of arabinose, small arabinan oligosaccharides, and linear arabinan. $1 \mathrm{MC} 16$ possesses two ABC transporter systems (genes 4-6 and 19-21). The first transporter system is orthologous to the $G$. stearothermophilus T-6 araT, AraE, araG transporter, while the second has no orthologs in T-6. While the three component araT, AraE, araG transporter system is annotated as an arabinose transport system, the three genes show remarkable homology to the rbsA, rbsB, rbsC cluster responsible for transport of ribose in B. subtilis (Woodson and Devine, 1994; Strauch, 1995), and may actually function as a ribose transport system within the arabinan-arabinose cluster.

Strain 1MC16 lacks the eight-gene cluster containing the extracellular arabinanase, transporter and intracellular endo- $\alpha$ arabinanase, $\alpha$-L-arabinofuranosidase, and arabinopyranosidase (genes 11-18) present in the T-6 cluster. 1MC16 possesses all metabolic enzymes needed for arabinose and potentially arabinooligosaccharide metabolism (genes 7-10 and 2327), suggesting that the organism can utilize arabinose in arabinoxylan oligosaccharides, extracellular arabinose and possibly small arabinan oligosaccharides.

The most complex arabinose metabolic system is present in 56T3. 56T3 possesses an arabinose cluster that is orthologous to the $1 \mathrm{MC} 16$ cluster described above. However, in addition to this cluster, 56T3 possesses a seven-gene arabinan-utilization cluster consisting of a transcription regulator, three-component $\mathrm{ABC}$ transporter system, and three intracellular proteins, an arabinase, an arabinofuranosidase, and an annotated oxidoreductase with unknown function (Table 7). This cluster is located adjacent to the galactose utilization cluster in 56T3 and it is not orthologous to the clusters found in T-6, MC52, and MC61, but is closely related to the cluster found in the unpublished genome of Geobacillus sp. MAS1 (NCBI/RefSeq: AYSF01000001 through AYSF01000006) as well as distantly related to clusters in Bacillus spp. and Anoxybacillus tepidamans PS2. 


\section{A $>$ IolG $>$ IolG $>A B C>A B C>A B C>$ Lacl $>$ IolG $>$ IolD $>$ IolE $>$ IolB $>$ IolC $>$ IolA $>\mathrm{FbaA}>A B C$}

\section{B $>$ Lacl $>$ IolG $>$ IolG $>$ IolG $>A B C>A B C>A B C>I 0 l l>I o l D>I 0|E>I o l B>I o l C>I 0| A>F b a A>A B C$}

FIGURE 3 | Diagram of inositol utilization clusters. (A) Cluster found in 1MC16, G. thermodenitrificans DSM 465 and G. thermodenitrificans NG80-2. (B) Cluster found in G. kaustophilus HTA426, Geobacillus subterraneus PSS2, G. thermoglucosidasius M10EXG, and G. thermocatenulatus GS-1.

TABLE 6 | Arabinose and ribose metabolic cluster.

\begin{tabular}{|c|c|c|c|c|c|c|c|}
\hline & Annotation & YS93 & $1 \mathrm{MC16}$ & MC52 & MC61 & $56 \mathrm{~T} 2$ & $56 \mathrm{T3}$ \\
\hline 1 & Sugar ABC transporter sugar-binding protein & - & 1543 & - & - & - & 1614 \\
\hline 2 & Multi-sensor signal transduction histidine kinase & - & 1544 & - & - & - & 1615 \\
\hline 3 & AraC family transcriptional regulator & - & 1546 & - & - & - & 1616 \\
\hline 4 & $\mathrm{ABC}$ transporter substrate-binding protein & - & 1547 & - & - & - & 1617 \\
\hline 5 & ABC transporter & - & 1548 & - & - & - & 1618 \\
\hline 6 & Inner-membrane translocator & - & 1549 & - & - & - & 1619 \\
\hline 7 & GntR family transcriptional regulator & - & 1550 & 1867 & 2737 & 1890 & 1620 \\
\hline 8 & L-ribulose-5-phosphate 4-epimerase & - & 1551 & 1866 & 2736 & 1889 & 1621 \\
\hline 9 & L-ribulokinase & - & 1552 & 1865 & 2735 & 1888 & 1622 \\
\hline 10 & $\mathrm{~L}$-arabinose isomerase & - & 1553 & 1864 & 2734 & 1887 & 1623 \\
\hline 11 & Arabinopyranosidase & - & - & 1863 & 2733 & - & - \\
\hline 12 & Intracellular endo- $\alpha-(1-5)-L$-arabinanase & - & - & 1862 & 2732 & - & - \\
\hline 13 & Family 1 extracellular solute-binding protein & - & - & 1861 & 2731 & - & - \\
\hline 14 & Binding-protein-dependent transporters inner membrane protein & - & - & 1860 & 2730 & - & - \\
\hline 15 & Sugar ABC transporter permease & - & - & 1859 & 2729 & - & - \\
\hline 16 & Extracellular arabinanase & - & - & 1858 & 2728 & - & - \\
\hline 17 & $\alpha-L$-arabinofuranosidase & - & - & 1857 & 2727 & - & - \\
\hline 18 & Unknown 88 a.a. protein & - & - & 1856 & 2726 & - & - \\
\hline 19 & Family 1 extracellular solute-binding protein & - & 1554 & - & - & - & 1624 \\
\hline 20 & Binding-protein-dependent transporters inner membrane protein & - & 1555 & - & - & - & 1625 \\
\hline 21 & Sugar ABC transporter permease & - & 1556 & - & - & - & 1626 \\
\hline 22 & $\alpha-\mathrm{N}$-arabinofuranosidase & - & - & - & - & 1885 & - \\
\hline 23 & $\alpha$-L-arabinofuranosidase & - & 1557 & 1855 & 2725 & 1884 & 1627 \\
\hline 24 & Oxidoreductase domain-containing protein & - & 1558 & 1854 & 2724 & 1883 & 1628 \\
\hline 25 & Aldose 1-epimerase & - & 1569 & 1853 & 2723 & 1878 & 1629 \\
\hline 26 & HAD-superfamily hydrolase & - & 1559 & 1852 & 2722 & 1881 & 1630 \\
\hline 27 & Glycerol-1-phosphate dehydrogenase & - & 1560 & 1851 & 2721 & 1880 & 1631 \\
\hline 28 & $\beta$-L-arabinofuranosidase & - & - & 1850 & 2720 & - & - \\
\hline
\end{tabular}

\section{Xylose and Xylan Metabolism}

As expected from the fermentation results, all six strains possess gene clusters for xylan degradation and metabolism. Xylose and xylan are transported and metabolized by all six strains via a large single cluster containing as many as 32 genes (De Maayer et al., 2014) (Table 8). A single secreted xylanase (XynA) degrades xylan into oligosaccharides. Two, three-gene ABC transporters of xylose and xylooligosaccharides are present in all six strains (shown in bold, genes 3, 4, 5 and 10, 11, 12). In addition, strains 56T2 and C56-T3 contain a third three-gene $\mathrm{ABC}$ transporter $(27,28,29)$. The transported oligosaccharides are further degraded into monosaccharides within the cell by an intracellular xylanase (XynA2), xylosidases (XynB and XynB2) and an $\alpha$-glucuronidase (AguA) similar to those described in $G$. stearothermophilus T-6 (Shulami et al., 1999). The enzymes for glucuronate utilization are coded for within the cluster (genes 16, $18,19,20$ ), as are the enzymes for xylose utilization (genes 31 and 32).

\section{Cellobiose and Fructose Metabolism}

Cellobiose and fructose are utilized by all six strains via dedicated phosphotransferase system (PTS) transporter systems. In all six strains, orthologous clusters code for three-component phosphotransferase system (PTS) transporter systems that uses 
phosphoenolpyruvate to transport the sugar into the cell and phosphorylate it, generating intracellular fructose-1-phosphate or cellobiose-6-phosphate. A MerR family transcriptional

TABLE 7 | 56T3 Arabinose and arabinan metabolic cluster.

\begin{tabular}{lr}
\hline Annotation & Gene \\
\hline Transcriptional regulator, ArsR family & 1352 \\
Extracellular solute-binding protein family 1 & 1353 \\
Binding-protein-dependent transport systems inner membrane component & 1354 \\
Binding-protein-dependent transport systems inner membrane component & 1355 \\
GH43 Intracellular endo- $\alpha$-(1-5)-L-arabinanase & 1356 \\
GH2 $\alpha$-L-arabinofuranosidase & 1357 \\
Oxidoreductase & 1358 \\
Galactokinase, GalK & 1361 \\
UDP-glucose 4-epimerase, GalE & 1362 \\
Gal-1-phosphate uridylyltransferase, GalT & 1363 \\
Transcriptional regulator, Lacl family & 1364
\end{tabular}

regulator controls cellobiose uptake in all six strains. The six cellobiose utilization clusters also contain a gene coding for 6-phospho- $\beta$-glucosidase, which converts cellobiose-6phosphate to glucose and glucose-6-phosphate. A DeoR family transcriptional regulator controls fructose uptake in all six strains. The six fructose utilization clusters also contain a gene coding for 1-phosphofructokinase, which converts fructose-1-phosphate to fructose-1,6-diphosphate.

\section{Carbohydrate Clusters Found Outside the $\sim 200$ Kb Region Starch Metabolism}

Two separate gene clusters are dedicated to degradation of starch, one targeting $\alpha$-1,4-linked glucooligosaccharides, and one targeting $\alpha-1,6$-linked glucooligosaccharides. Genomic analysis indicates that five of the six strains (YS93 being the exception) possess the ability to degrade $\alpha$-1,4-linked starch and starchderived $\alpha$-1,4-linked glucans. In the five strains, an orthologous cluster codes for a secreted $\alpha$-amylase, a three-component ABC

TABLE 8 | Xylose and xylan metabolic cluster.

\begin{tabular}{|c|c|c|c|c|c|c|c|}
\hline & Annotation & YS93 & $1 \mathrm{MC16}$ & MC52 & MC61 & $56 \mathrm{~T} 2$ & $56 \mathrm{T3}$ \\
\hline 1 & Integral membrane sensor signal transduction histidine kinase & 2272 & 1564 & 1849 & 2719 & 1877 & 1634 \\
\hline 2 & AraC family transcriptional regulator & 2271 & 1565 & 1848 & 2718 & 1876 & 1635 \\
\hline 3 & Family 1 extracellular solute-binding protein & 2270 & 1566 & 1846 & 2716 & 1875 & 1636 \\
\hline 4 & Binding-protein-dependent transporters inner membrane component & 2269 & 1567 & 1845 & 2715 & 1874 & 1637 \\
\hline 5 & Binding-protein-dependent transporters inner membrane component & 2268 & 1568 & 1844 & 2714 & 1873 & 1638 \\
\hline 6 & Aldose 1-epimerase & 2267 & 1569 & 1843 & 2713 & - & 1639 \\
\hline 7 & Polysaccharide deacetylase & 2266 & 1570 & 1842 & 2712 & - & 1640 \\
\hline 8 & Xylan 1,4-beta-xylosidase & 2265 & 1571 & 1841 & 2711 & 1872 & 1641 \\
\hline 9 & Endo-1,4-beta-xylanase & 2264 & 1572 & 1840 & 2710 & 1871 & 1642 \\
\hline 10 & Family 1 extracellular solute-binding protein & 2262 & 1574 & 1839 & 2709 & 1873 & 1643 \\
\hline 11 & Binding-protein-dependent transporters inner membrane component & 2261 & 1575 & 1838 & 2708 & 1874 & 1644 \\
\hline 12 & Binding-protein-dependent transporters inner membrane component & 2260 & 1577 & 1837 & 2707 & 1875 & 1645 \\
\hline 13 & $\alpha$-glucuronidase & 2259 & 1578 & 1836 & 2706 & 1870 & 1646 \\
\hline 14 & Xylan 1,4-beta-xylosidase & 2258 & 1579 & 1835 & 2705 & 1869 & 1647 \\
\hline 15 & PfkB domain-containing protein & 2257 & 1580 & 1834 & 2704 & - & 1648 \\
\hline 16 & 2-dehydro-3-deoxyphosphogluconate aldolase & 2256 & 1581 & 1833 & 2703 & 1867 & 1649 \\
\hline 17 & GntR family transcriptional regulator & 2255 & 1582 & 1832 & 2702 & 1866 & 1650 \\
\hline 18 & Uronate isomerase & 2254 & 1583 & - & - & - & 1651 \\
\hline 19 & Mannonate dehydratase & 2253 & 1584 & 1828 & 2699 & 1864 & 1652 \\
\hline 20 & Short-chain dehydrogenase & 2252 & 1585 & 1829 & 2698 & 1863 & 1653 \\
\hline 21 & Hypothetical protein & 2251 & 1586 & 1827 & 2697 & - & 1654 \\
\hline 22 & Endo-1,4-beta-xylanase & 2250 & 1587 & 1825 & 2695 & 1860 & 1655 \\
\hline 23 & Hypothetical protein & 2247 & 1588 & 1823 & 2693 & 1858 & 1656 \\
\hline 24 & G-D-S-L family lipolytic protein & - & 1589 & 1822 & 2692 & 1857 & 1657 \\
\hline 25 & AraC family transcriptional regulator & - & - & - & - & 1856 & 1658 \\
\hline 26 & Integral membrane sensor signal transduction histidine kinase & - & - & - & - & 1855 & 1659 \\
\hline 27 & Family 1 extracellular solute-binding protein & - & - & - & - & 1854 & 1660 \\
\hline 28 & Binding-protein-dependent transporters inner membrane component & - & - & - & - & 1853 & 1661 \\
\hline 29 & ABC transporter permease & - & - & - & - & 1852 & 1662 \\
\hline 30 & Arabinofuranosidase/xylosidase & - & 1564 & - & - & 1851 & - \\
\hline 31 & Xylose isomerase & 2243 & 1565 & 1818 & 2688 & 1850 & 1664 \\
\hline 32 & Xylulokinase & 2242 & 1566 & 1817 & 2687 & 1849 & 1665 \\
\hline
\end{tabular}


transporter system, and an intracellular $\alpha$-amylase, all under the control of a LacI family transcriptional regulator (Table 9). The secreted $\alpha$-amylase, transcriptional regulator and the threecomponent $\mathrm{ABC}$ transporter system show $>90 \%$ identity among the five strains. The intracellular $\alpha$-amylase genes of strains MC52, 12MC61, C56T3 and 56T2 code for 588 a.a. proteins with $>90 \%$ identity to each other, but in $1 \mathrm{MC16}$, the gene is truncated, coding for a 297 a.a. protein corresponding to the N-terminal domain of the 588 a.a. protein. In addition to the six-gene cluster, strains MC52, MC61, C56T3, and 56T2 possess an identical, two-gene insert containing a different secreted $\alpha$-amylase (amyS) and a secreted amylopullulanase, located far downstream from the starch cluster. The utilization of three distinct secreted enzymes for degradation of starch is a highly unusual strategy for these Geobacillus species. In contrast, these Geobacillus species degrade xylan and arabinan using one secreted enzyme each, and no other secreted polysaccharide-degrading metabolic enzymes are secreted. None of the six strains contain the Geobacillus high molecular weight amylase that associates with the Slayer (Ferner-Ortner-Bleckmann et al., 2009), or the Geobacillus maltose-producing high molecular weight amylase (Diderichsen and Christiansen, 1988).

In all six strains, an orthologous cluster codes for a three-component $\mathrm{ABC}$ transporter system, and an intracellular $\alpha$-1,6-glucosidase, all under the control of a LacI family transcriptional regulator. The transcriptional regulator and the three-component $\mathrm{ABC}$ transporter system show $>90 \%$ identity among the six strains, while the $\alpha$-1,6-glucosidase shows a lower identity (70\%). The cluster may act synergistically with the starch cluster to take up and degrade the branched regions of partially degraded amylopectin, or the cluster may take up and degrade more highly branched substrates such as pullulan or glycogen fragments.

\section{Galactose and Galactoside Utilization}

The six strains each show distinct metabolic capabilities for galactose utilization (Table 10). All six strains utilize galactose via the Leloir pathway of GalK, GalT, and GalE (Holden et al., 2003), similar to the pathway in most organisms including $B$. subtilis (Chai et al., 2012). The pathway in all six strains is under the control of a LacI family transcriptional regulator. C56T3 possesses only the Leloir pathway and no transporter or galactosidase genes, suggesting a limited ability to utilize exogenous galactose or galactans. 1MC16 lacks transporter genes, but possesses a single $\beta$-galactosidase, suggesting $1 \mathrm{MC} 16$ is able to utilize galactose linked to xylan or arabinan that was transported into the cell via xylan or arabinan transporter systems. Similarly, strain YS93 lacks transporter genes, but possesses a single intracellular $\alpha$-galactosidase, suggesting $1 \mathrm{MC} 16$ is able to utilize galactose linked to sucrose, xylan or arabinan that was transported into the cell via the corresponding transporter system. 56T2 possesses transporter genes and genes for two intracellular $\beta$-galactosidases, suggesting the ability to utilize lactose and galactan oligosaccharides. Finally,

TABLE 9 | $\alpha$-1,4-linked Glucooligosaccharide metabolic cluster.

\begin{tabular}{|c|c|c|c|c|c|c|}
\hline Annotation & YS93 & $1 \mathrm{MC16}$ & MC52 & MC61 & $56 \mathrm{~T} 2$ & $56 \mathrm{T3}$ \\
\hline$\alpha$-amylase (cyclomaltodextrinase) & - & 0573 & 0632 & 1510 & 0721 & 2858 \\
\hline Extracellular solute-binding protein family 1 & - & 0572 & 0633 & 1511 & 0722 & 2857 \\
\hline Binding-protein-dependent transport systems inner membrane component & - & 0571 & 0634 & 1512 & 0723 & 2856 \\
\hline Binding-protein-dependent transport systems inner membrane component & - & 0570 & 0635 & 1513 & 0724 & 2855 \\
\hline Secreted $\alpha$-amylase & - & 0569 & 0636 & 1514 & 0725 & 2854 \\
\hline Transcriptional regulator, Lacl family & - & 0568 & 0637 & 1515 & 0726 & 2853 \\
\hline Secreted amylopullulanase & - & - & 3302 & 3272 & 2870 & 3189 \\
\hline Secreted $\alpha$-amylase (AmyS) & - & - & 3303 & 3273 & 2871 & 3190 \\
\hline
\end{tabular}

TABLE 10 | Galactose and galactoside metabolic cluster.

\begin{tabular}{|c|c|c|c|c|c|c|}
\hline Annotation/corresponding gene & YS93 & $1 \mathrm{MC16}$ & MC52 & MC61 & $56 \mathrm{~T} 2$ & $56 \mathrm{T3}$ \\
\hline$\alpha$-galactosidase & 1518 & - & 2132 & 0528 & - & - \\
\hline Uncharacterized protein & 1519 & - & 2131 & 0529 & - & - \\
\hline$\beta$-galactosidase, GH42 & - & - & 2130 & 0530 & 2119 & - \\
\hline Extracellular solute-binding protein family 1 & - & - & 2129 & 0531 & 2118 & - \\
\hline Binding-protein-dependent transport systems inner membrane component & - & - & 2128 & 0532 & 2117 & - \\
\hline Binding-protein-dependent transport systems inner membrane component & - & - & 2127 & 0533 & 2116 & - \\
\hline$\beta$-galactosidase, $\mathrm{GH} 2$ & - & 1068 & 2126 & 0534 & 2115 & - \\
\hline Galactokinase, GalK & 1520 & 1066 & 2124 & 0536 & 2113 & 1361 \\
\hline UDP-glucose 4-epimerase, GalE & 1521 & 1065 & 2123 & 0537 & 2112 & 1362 \\
\hline Gal-1-phosphate uridylyltransferase, GalT & 1522 & 1064 & 2122 & 0538 & 2111 & 1363 \\
\hline Transcriptional regulator, Lacl family & 1523 & 1063 & 2121 & 0539 & 2110 & 1364 \\
\hline
\end{tabular}


strains MC52 and MC61 possess transporter genes and genes for two intracellular $\beta$-galactosidases and one intracellular $\alpha$ galactosidase, suggesting the ability to utilize a wide range of galactose-containing oligosaccharides. None of the strains possess the extracellular $\alpha$-galactosidase identified in one strain of G. stearothermophilus (Talbot and Sygusch, 1990). The intracellular $\alpha$-galactosidases show significant differences in sequence. The intracellular $\alpha$-galactosidases of MC52 and MC61 share $100 \%$ identity with each other and $98 \%$ identity with the $G$. stearothermophilus $\alpha$-galactosidase identified as AgaA (Merceron et al., 2012). The intracellular $\alpha$-galactosidase of YS93 shares only $81-82 \%$ identity with G. stearothermophilus AgaA and the $\alpha-$ galactosidases of MC52 and MC61, but shares 93\% identity with the G. stearothermophilus $\alpha$-galactosidase identified as AgaN (Fridjonsson et al., 1999).

The MC52 and MC61 $\beta$-galactosidase, GH42 share 99\% identity with the $G$. stearothermophilus $\beta$-galactosidase GanB (Solomon et al., 2013), while the 56T2 shares 96\% identity with the G. stearothermophilus enzyme. The second $\beta$-galactosidase, $\beta$-galactosidase GH2 of MC52 and MC61 share 100\% identity with each other and 96\% identity with the 56T2 enzyme. The gene for this $\beta$-galactosidase appears to be uncommon among thermophiles, being identified only in the genome of Geobacillus sp. Strain WSUCF1 (Bhalla et al., 2013) (99\% identity to MC52 and MC61) and Anoxybacillus flavithermus TNO-09.006 (Caspers et al., 2013) (98\% identity to MC52 and MC61). This $\mathrm{GH} 2 \beta$-galactosidase is related to similar enzymes in mesophilic species such as B. halodurans strain ATCC BAA-125 (Takami et al., 2000) (69\% identity to MC52 and MC61) and Paenibacillus polymyxa strain CR1 (Eastman et al., 2014) (67\% identity to MC52 and MC61).

\section{Sucrose Metabolism}

Sucrose is utilized by three of the six strains (MC52, MC61, and YS93) via a dedicated phosphotransferase system (PTS) transporter system. In all three strains, orthologous clusters code for three-component phosphotransferase system (PTS) transporter systems that uses phosphoenolpyruvate to transport the sugar into the cell and phosphorylate it, generating intracellular sucrose-6-phosphate under control of a MtlR family transcriptional regulator. The three sucrose utilization clusters also contain a gene coding for sucrose-6-phosphate hydrolase, which converts sucrose-6-phosphate to fructose and glucose-6phosphate. The remaining three strains have no sucrose uptake system of any kind.

\section{Discussion}

In this work we report the whole genome sequences of six new xylanolytic Geobacillus strains along with the genomic analysis of their capability to degrade carbohydrates. The six sequenced Geobacillus strains described here have a range of GC contents from 43.9 to $52.5 \%$. Based on phylogenetic analysis, three of the strains, MC52, MC61, and 56T3 may be members of a single new species, and 56T2 may also be a member of a new species. The remaining two strains clade with named Geobacillus species (Zeigler, 2005).
Whole genome sequencing and analysis of these six strains gives a first look at the wide range of carbohydrate degradation capabilities (Table 11) of Geobacillus species. All six strains are predicted to utilize fructose, arabinose, xylose, mannitol, gluconate, xylan, and pullulan ( $\alpha$-1,6-glucosides). The gene clusters have identical organization and the individual proteins have a high percent identity to their homologs. Significant differences exist in the ability of the sequenced strains to utilize inositol, sucrose, lactose, $\alpha$-mannosides, $\alpha$-1,4-glucosides and arabinan. None of the strains was able to utilize all of these carbohydrates. Complete or partial utilization pathways were present or were completely absent in a strain-specific pattern. The proteins utilized in degradation of these carbohydrates showed greater strain-to-strain variation than the proteins utilized in degradation of fructose, arabinose, xylose, mannitol, gluconate, xylan, and pullulan.

Our group has sequenced and analyzed the genomes of a number of biomass degraders including three Cellulomonas spp. (Christopherson et al., 2013), Bacillus cellulosilyticus (Mead et al., 2013), Fibrobacter succinogenes (Brumm et al., 2011b; Suen et al., 2011) and Dictyoglomus turgidum (Brumm et al., 2011a). Comparison of the genomes of these biomass degraders to the six Geobacillus spp., show three major differences between the strategies employed by the Geobacillus and these other diverse organisms.

The Geobacillus spp. in this work were selected for their ability to hydrolyze MUX or MUC. Based on enzymatic assays, all six strains were able to utilize xylan, but only two strains, MC52 and MC61, were able to utilize arabinan. The genes for these activities were found in a large, conserved pentosan degradation cluster. Five of the six pentosan clusters include a region involved in arabinan degradation and all six include

\begin{tabular}{|c|c|c|c|c|c|c|}
\hline & YS93 & $1 \mathrm{MC16}$ & MC52 & MC61 & $56 \mathrm{~T} 2$ & $56 \mathrm{T3}$ \\
\hline Fructose & PTS & PTS & PTS & PTS & PTS & PTS \\
\hline Arabinose & $\mathrm{ABC}$ & $\mathrm{ABC}$ & $\mathrm{ABC}$ & $\mathrm{ABC}$ & $\mathrm{ABC}$ & $A B C$ \\
\hline Xylose & $\mathrm{ABC}$ & $\mathrm{ABC}$ & $\mathrm{ABC}$ & $\mathrm{ABC}$ & $\mathrm{ABC}$ & $A B C$ \\
\hline Galactose & $\mathrm{ABC}$ & $\mathrm{ABC}$ & $\mathrm{ABC}$ & $\mathrm{ABC}$ & $\mathrm{ABC}$ & - \\
\hline Gluconate & PER & PER & PER & PER & PER & PER \\
\hline Inositol & - & PTS & - & - & - & - \\
\hline Mannitol & PTS & PTS & PTS & PTS & PTS & PTS \\
\hline Cellobiose & PTS & PTS & PTS & PTS & PTS & PTS \\
\hline Sucrose & PTS & - & PTS & PTS & - & - \\
\hline Lactose & - & - & $\mathrm{ABC}$ & $\mathrm{ABC}$ & - & - \\
\hline Starch & - & $\mathrm{ABC}$ & $\mathrm{ABC}$ & ABC & $\mathrm{ABC}$ & $\mathrm{ABC}$ \\
\hline$\alpha$-Mannosides & - & $\mathrm{ABC}$ & - & - & - & - \\
\hline Arabinan & - & - & $\mathrm{ABC}$ & $\mathrm{ABC}$ & - & - \\
\hline Xylan & $\mathrm{ABC}$ & $\mathrm{ABC}$ & $\mathrm{ABC}$ & $\mathrm{ABC}$ & $\mathrm{ABC}$ & $A B C$ \\
\hline Panose/pullulan & $\mathrm{ABC}$ & $\mathrm{ABC}$ & $\mathrm{ABC}$ & $\mathrm{ABC}$ & $\mathrm{ABC}$ & $A B C$ \\
\hline
\end{tabular}

Gene clusters for utilization of listed substrates as described in text. $A B C$, three component $A B C$ transporter system; PTS, three component phosphotransferase system; $P E R$, permease system. 
a region for xylan degradation, with over 50 possible genes in the combined pentosan cluster. The organization of the genes within the cluster is highly conserved in all the Geobacillus strains studied, and more importantly, none of the genes involved in pentosan metabolism are found outside this cluster. In the six diverse biomass degraders, pentosan degradation genes are not clustered, but are distributed randomly throughout the genomes. Random distributions of pentosan degradation genes are seen in other biomass degraders such as Bacillus, Clostridium, and Streptomyces species. These observations suggest that the large, single pentosan degradation cluster appears to be a unique feature of Geobacillus spp. The evolutionary advantages of a single cluster versus a random distribution are unclear, but suggest a single cluster may be an adaptation to life under extreme conditions. The Geobacillus pentosan degradation cluster is part of a $\sim 200 \mathrm{~kb}$ unique super-cluster, containing five to eight distinct carbohydrate degradation clusters in a single genomic region, a feature not seen in other sequenced strains in related genera.

The Geobacillus spp. are also unique in their dependence on a minimum number of secreted enzymes for utilization of carbohydrates. Only two secreted enzymes, a xylanase and an arabinanase, are used in degradation of xylan and arabinan. Starch degradation utilizes three secreted enzymes. None of the Geobacillus spp. secrete xylosidases or arabinofuranosidases. In contrast to the Geobacillus spp., most other Gram-positive pentosan-degraders secrete multiple xylanases as well as multiple xylosidases. For example, Cellulomonas flavigena secretes 19 xylanases and 3 xylosidases, Cellulomonas fimi secretes 6 xylanases and 4 xylosidases, and Cellulomonas gilvus secretes 6 xylanases and 5 xylosidases (Christopherson et al., 2013). In further contrast to the Geobacillus spp., many other Grampositive pentosan-degraders secrete combinations of other biomass-degrading enzymes such as cellulases, mannanases, xyloglucanases, pectinases, and pectate lyases. The genomes of the Geobacillus spp. lack orthologs of these secreted enzymes, indicating that Geobacillus spp. may target a limited range of carbohydrate polymers in intact biomass, or degrade biomass as

\section{References}

Abdul Rahman, M. B., Karjiban, R. A., Salleh, A. B., Jacobs, D., Basri, M., Thean Chor, A. L., et al. (2009). Deciphering the flexibility and dynamics of Geobacillus zalihae strain T1 lipase at high temperatures by molecular dynamics simulation. Protein Pept. Lett. 16, 1360-1370. doi: 10.2174/092986609789353763

Anand, A., Kumar, V., and Satyanarayana, T. (2013). Characteristics of thermostable endoxylanase and beta-xylosidase of the extremely thermophilic bacterium Geobacillus thermodenitrificans TSAA1 and its applicability in generating xylooligosaccharides and xylose from agro-residues. Extremophiles 17, 357-366. doi: 10.1007/s00792-013-0524-x

Apweiler, R., Bairoch, A., Wu, C. H., Barker, W. C., Boeckmann, B., Ferro, S., et al. (2004). UniProt: the Universal Protein knowledgebase. Nucleic Acids Res. 32, D115-D119. doi: 10.1093/nar/gkh131

Balan, A., Ibrahim, D., Abdul Rahim, R., and Ahmad Rashid, F. A. (2012). Purification and characterization of a Thermostable Lipase from Geobacillus thermodenitrificans IBRL-nra. Enzyme Res. 2012:987523. doi: $10.1155 / 2012 / 987523$ part of a thermophilic consortium whose other members possess these activities.

Another unique feature of the Geobacillus pentosan cluster enzymes is the lack of targeting by attached carbohydrate binding modules (CBM) (Lombard et al., 2014). CBM modules are believed to improve enzyme efficiency by providing specific noncatalytic binding to the correct substrate (Boraston et al., 2004). CBM modules are present in many of the xylanases produced by thermophilic Gram-positive organisms including Clostridium thermocellum and Caldicellulosiruptor species (http://www.cazy. org/) (Lombard et al., 2014). The lack of CBM modules may indicate that the Geobacillus enzymes predate the evolution of CBM modules. Alternately, the lack of CBM modules make give Geobacillus enzymes the ability to utilize a broader range of substrates at the cost of a slower rate of hydrolysis.

The sequencing and genomic analysis of these six Geobacillus spp. confirms the belief that Geobacillus spp. are an excellent source of a variety of thermophilic enzymes with industrial applications. The variety of enzymes observed in a number of pathways, as well as the absence of previously identified Geobacillus enzymes such as the maltogenic (Diderichsen and Christiansen, 1988) and high molecular weight (Ferner-OrtnerBleckmann et al., 2009) amylases suggest that sufficient genetic variability exists with the genus to supply additional new enzymes with novel applications.

\section{Acknowledgments}

This work was funded by the US Department of Energy Great Lakes Bioenergy Research Center (WI, USA; US Department of Energy Biological and Environmental Research Office of Science DE-FC02-07ER64494). We would like to thank the sequencing, production, and annotation teams at the Joint Genome Institute and Oak Ridge National Laboratory for their help and expertise in generating the draft genome sequences used in this study. In particular, we acknowledge the help of A. Christine Munk and Lynne A. Goodwin. We would also like to thank Dr. Daniel Zeigler his review of the manuscript during its preparation.

Bhalla, A., Bischoff, K. M., Uppugundla, N., Balan, V., and Sani, R. K. (2014). Novel thermostable endo-xylanase cloned and expressed from bacterium Geobacillus sp. WSUCF1. Bioresour Technol. 165, 314-318. doi: 10.1016/j.biortech.2014.03.112

Bhalla, A., Kainth, A. S., and Sani, R. K. (2013). Draft Genome Sequence of Lignocellulose-Degrading Thermophilic Bacterium Geobacillus sp. Strain WSUCF1. Genome Announc. 1:e00595-13. doi: 10.1128/genomeA. 00595-13

Boraston, A. B., Bolam, D. N., Gilbert, H. J., and Davies, G. J. (2004). Carbohydratebinding modules: fine-tuning polysaccharide recognition. Biochem. J. 382(Pt 3), 769-781. doi: 10.1042/BJ20040892

Bravman, T., Zolotnitsky, G., Belakhov, V., Shoham, G., Henrissat, B., Baasov, T., et al. (2003). Detailed kinetic analysis of a family 52 glycoside hydrolase: a betaxylosidase from Geobacillus stearothermophilus. Biochemistry 42, 10528-10536. doi: 10.1021/bi034505o

Brumm, P., Hermanson, S., Hochstein, B., Boyum, J., Hermersmann, N., Gowda, K., et al. (2011a). Mining Dictyoglomus turgidum for enzymatically active carbohydrases. Appl. Biochem. Biotechnol. 163, 205-214. doi: 10.1007/s12010010-9029-6 
Brumm, P. J., Hebeda, R. E., and Teague, W. M. (1991). Purification and characterization of the commercialized, cloned Bacillus megaterium $\alpha$-amylase. Part I: purification and hydrolytic properties. Starch/Stärke 43, 315-319. doi: 10.1002/star.19910430806

Brumm, P., Mead, D., Boyum, J., Drinkwater, C., Gowda, K., Stevenson, D., et al. (2011b). Functional annotation of Fibrobacter succinogenes S 85 carbohydrate active enzymes. Appl. Biochem. Biotechnol. 163, 649-657. doi: 10.1007/s12010010-9070-5

Brux, C., Ben-David, A., Shallom-Shezifi, D., Leon, M., Niefind, K., Shoham, G., et al. (2006). The structure of an inverting GH43 beta-xylosidase from Geobacillus stearothermophilus with its substrate reveals the role of the three catalytic residues. J. Mol. Biol. 359, 97-109. doi: 10.1016/j.jmb.2006. 03.005

Cameron, M., Williams, H. E., and Cannane, A. (2004). Improved gapped alignment in BLAST. IEEE/ACM Trans. Comput. Biol. Bioinform. 1, 116-129. doi: 10.1109/TCBB.2004.32

Caspers, M. P., Boekhorst, J., Abee, T., Siezen, R. J., and Kort, R. (2013). Complete Genome Sequence of Anoxybacillus flavithermus TNO-09.006, a Thermophilic sporeformer associated with a dairy-processing environment. Genome Announc. 1:e00010-13. doi: 10.1128/genomeA.00010-13

Chai, Y., Beauregard, P. B., Vlamakis, H., Losick, R., and Kolter, R. (2012). Galactose metabolism plays a crucial role in biofilm formation by Bacillus subtilis. MBio 3, e00184-e00112. doi: 10.1128/mBio.00184-12

Chen, X. G., Stabnikova, O., Tay, J. H., Wang, J. Y., and Tay, S. T. (2004). Thermoactive extracellular proteases of Geobacillus caldoproteolyticus, sp. nov., from sewage sludge. Extremophiles 8, 489-498. doi: 10.1007/s00792-0040412-5

Chen, Y., Yu, P., Luo, J., and Jiang, Y. (2003). Secreted protein prediction system combining CJ-SPHMM, TMHMM, and PSORT. Mamm. Genome 14, 859-865. doi: 10.1007/s00335-003-2296-6

Cho, S. G., and Choi, Y. J. (1999). Catabolite repression of the xylanase gene (xynA) expression in Bacillus stearothermophilus no. 236 and B. subtilis. Biosci. Biotechnol. Biochem. 63, 2053-2058. doi: 10.1271/bbb.63.2053

Choi, I. D., Kim, H. Y., and Choi, Y. J. (2000). Gene cloning and characterization of alpha-glucuronidase of Bacillus stearothermophilus no. 236. Biosci. Biotechnol. Biochem. 64, 2530-2537. doi: 10.1271/bbb.64.2530

Christopherson, M. R., Suen, G., Bramhacharya, S., Jewell, K. A., Aylward, F. O., Mead, D., et al. (2013). The genome sequences of Cellulomonas fimi and Cellvibrio gilvus reveal the cellulolytic strategies of two facultative anaerobes, transfer of Cellvibrio gilvus to the genus Cellulomonas, and proposal of Cellulomonas gilvus sp. nov. PLoS ONE 8:e53954. doi: 10.1371/journal.pone.0053954

Consortium, T. U. (2013). Update on activities at the Universal Protein Resource (UniProt) in 2013. Nucleic Acids Res. 41, D43-D47. doi: 10.1093/nar/gks1068

Consortium, T. U. (2014). Activities at the Universal Protein Resource (UniProt). Nucleic Acids Res. 42, D191-D198. doi: 10.1093/nar/gkt1140

Czjzek, M., Bravman, T., Henrissat, B., and Shoham, Y. (2004). Crystallization and preliminary X-ray analysis of family 39 beta-D-xylosidase from Geobacillus stearothermophilus T-6. Acta Crystallogr. Sect. D Biol. Cryst. 60(Pt 3), 583-585. doi: 10.1107/S0907444904001088

De Maayer, P., Brumm, P. J., Mead, D. A., and Cowan, D. A. (2014). Comparative analysis of the Geobacillus hemicellulose utilization locus reveals a highly variable target for improved hemicellulolysis. BMC Genomics 15:836. doi: 10.1186/1471-2164-15-836

de Miguel Bouzas, T., Barros-Velazquez, J., and Villa, T. G. (2006). Industrial applications of hyperthermophilic enzymes: a review. Protein Pept. Lett. 13, 645-651. doi: 10.2174/092986606777790548

Dersjant-Li, Y., Schulze, H., Schrama, J. W., Verreth, J. A., and Verstegen, M. W. (2001). Feed intake, growth, digestibility of dry matter and nitrogen in young pigs as affected by dietary cation-anion difference and supplementation of xylanase. J. Anim. Physiol. Anim. Nutr. 85, 101-109. doi: 10.1046/j.14390396.2001.00307.x

Diderichsen, B., and Christiansen, L. (1988). Cloning of a maltogenic alphaamylase from Bacillus stearothermophilus. FEMS Microbiol. Lett. 56, 53-60. doi: 10.1111/j.1574-6968.1988.tb03149.x

Eastman, A. W., Weselowski, B., Nathoo, N., and Yuan, Z. C. (2014). Complete Genome Sequence of Paenibacillus polymyxa CR1, a Plant Growth-Promoting Bacterium Isolated from the Corn Rhizosphere Exhibiting Potential for
Biocontrol, Biomass Degradation, and Biofuel Production. Genome Announc. e01218-13. doi: 10.1128/genomeA.01218-13

Ebrahimpour, A., Rahman, R. N., Basri, M., and Salleh, A. B. (2011). High level expression and characterization of a novel thermostable, organic solvent tolerant, 1,3-regioselective lipase from Geobacillus sp. strain ARM. Bioresour. Technol. 102, 6972-6981. doi: 10.1016/j.biortech.2011.03.083

Edgar, R. C. (2004). MUSCLE: multiple sequence alignment with high accuracy and high throughput. Nucleic Acids Res. 32, 1792-1797. doi: 10.1093/nar/gkh340

Feng, L., Wang, W., Cheng, J., Ren, Y., Zhao, G., Gao, C., et al. (2007). Genome and proteome of long-chain alkane degrading Geobacillus thermodenitrificans NG80-2 isolated from a deep-subsurface oil reservoir. Proc. Natl. Acad. Sci. U.S.A. 104, 5602-5607. doi: 10.1073/pnas.0609650104

Ferner-Ortner-Bleckmann, J., Huber-Gries, C., Pavkov, T., Keller, W., Mader, C., Ilk, N., et al. (2009). The high-molecular-mass amylase (HMMA) of Geobacillus stearothermophilus ATCC 12980 interacts with the cell wall components by virtue of three specific binding regions. Mol. Microbiol. 72, 1448-1461. doi: 10.1111/j.1365-2958.2009.06734.x

Fridjonsson, O., Watzlawick, H., Gehweiler, A., and Mattes, R. (1999). Thermostable alpha-galactosidase from Bacillus stearothermophilus NUB3621: cloning, sequencing and characterization. FEMS Microbiol. Lett. 176, 147-153. doi: 10.1016/S0378-1097(99)00231-1

Gerasimova, J., and Kuisiene, N. (2012). Characterization of the novel xylanase from the thermophilic Geobacillus thermodenitrificans JK1. Mikrobiologiia 81, 457-463. doi: 10.1134/S0026261712040066

Girio, F. M., Fonseca, C., Carvalheiro, F., Duarte, L. C., Marques, S., and BogelLukasik, R. (2010). Hemicelluloses for fuel ethanol: a review. Bioresour. Technol. 101, 4775-4800. doi: 10.1016/j.biortech.2010.01.088

Goodman, R. E., and Pederson, D. M. (1976). beta-Galactosidase from Bacillus stearothermophilus. Can. J. Microbiol. 22, 817-825. doi: 10.1139/m76-118

Griffiths-Jones, S., Bateman, A., Marshall, M., Khanna, A., and Eddy, S. R. (2003). Rfam: an RNA family database. Nucleic Acids Res. 31, 439-441. doi: 10.1093/nar/gkg006

Haki, G. D., and Rakshit, S. K. (2003). Developments in industrially important thermostable enzymes: a review. Bioresour. Technol. 89, 17-34. doi: 10.1016/S0960-8524(03)00033-6

Hawumba, J. F., Theron, J., and Brozel, V. S. (2002). Thermophilic proteaseproducing Geobacillus from Buranga hot springs in Western Uganda. Curr. Microbiol. 45, 144-150. doi: 10.1007/s00284-001-0116-3

Hirata, H., Fukazawa, T., Negoro, S., and Okada, H. (1986). Structure of a betagalactosidase gene of Bacillus stearothermophilus. J. Bacteriol. 166, 722-727.

Hirata, H., Negoro, S., and Okada, H. (1984). Molecular basis of isozyme formation of beta-galactosidases in Bacillus stearothermophilus: isolation of two betagalactosidase genes, bgaA and bgaB. J. Bacteriol. 160, 9-14.

Holden, H. M., Rayment, I., and Thoden, J. B. (2003). Structure and function of enzymes of the Leloir pathway for galactose metabolism. J. Biol. Chem. 278, 43885-43888. doi: 10.1074/jbc.R300025200

Hyatt, D., Chen, G. L., Locascio, P. F., Land, M. L., Larimer, F. W., and Hauser, L. J. (2010). Prodigal: prokaryotic gene recognition and translation initiation site identification. BMC Bioinformatics 11:119. doi: 10.1186/1471-2105-11-119

Itoi, Y., Horinaka, M., Tsujimoto, Y., Matsui, H., and Watanabe, K. (2006). Characteristic features in the structure and collagen-binding ability of a thermophilic collagenolytic protease from the thermophile Geobacillus collagenovorans MO-1. J. Bacteriol. 188, 6572-6579. doi: 10.1128/JB.00767-06

Jang, J. S., Kang, D. O., Chun, M. J., and Byun, S. M. (1992). Molecular cloning of a subtilisin J gene from Bacillus stearothermophilus and its expression in Bacillus subtilis. Biochem. Biophys. Res. Commun. 184, 277-282. doi: 10.1016/0006291X(92)91189-W

Jeong, S. T., Kim, H. K., Kim, S. J., Pan, J. G., Oh, T. K., and Ryu, S. E. (2001). Crystallization and preliminary X-ray analysis of a thermoalkalophilic lipase from Bacillus stearothermophilus L1. Acta Crystallogr. Sect. D Biol. Crystallogr. 57(Pt 9), 1300-1302. doi: 10.1107/S0907444901010332

Kamasaka, H., Sugimoto, K., Takata, H., Nishimura, T., and Kuriki, T. (2002). Bacillus stearothermophilus neopullulanase selective hydrolysis of amylose to maltose in the presence of amylopectin. Appl. Environ. Microbiol. 68, 1658-1664. doi: 10.1128/AEM.68.4.1658-1664.2002

Kim, M., Oh, H. S., Park, S. C., and Chun, J. (2014). Towards a taxonomic coherence between average nucleotide identity and 16S rRNA gene sequence 
similarity for species demarcation of prokaryotes. Int. J. Syst. Evol. Microbiol. 64(Pt 2), 346-351. doi: 10.1099/ijs.0.059774-0

Krogh, A., Larsson, B., von Heijne, G., and Sonnhammer, E. L. (2001). Predicting transmembrane protein topology with a hidden Markov model: application to complete genomes. J. Mol. Biol. 305, 567-580. doi: 10.1006/jmbi. 2000.4315

Lagesen, K., Hallin, P., Rodland, E. A., Staerfeldt, H. H., Rognes, T., and Ussery, D. W. (2007). RNAmmer: consistent and rapid annotation of ribosomal RNA genes. Nucleic Acids Res. 35, 3100-3108. doi: 10.1093/nar/gkm160

Lee, W. H., and Vega, V. B. (2004). Heterogeneity detector: finding heterogeneous positions in Phred/Phrap assemblies. Bioinformatics 20, 2863-2864. doi: 10.1093/bioinformatics/bth301

Liu, B., Zhang, N., Zhao, C., Lin, B., Xie, L., and Huang, Y. (2012). Characterization of a recombinant thermostable xylanase from hot spring thermophilic Geobacillus sp. TC-W7. J. Microbiol. Biotechnol. 22, 1388-1394. doi: $10.4014 / \mathrm{jmb} .1203 .03045$

Lombard, V., Golaconda Ramulu, H., Drula, E., Coutinho, P. M., and Henrissat, B. (2014). The carbohydrate-active enzymes database (CAZy) in 2013. Nucleic Acids Res. 42, D490-D495. doi: 10.1093/nar/gkt1178

Lowe, T. M., and Eddy, S. R. (1997). tRNAscan-SE: a program for improved detection of transfer RNA genes in genomic sequence. Nucleic Acids Res. 25, 955-964. doi: 10.1093/nar/25.5.0955

Machado, M., Magalhaes, W. C., Sene, A., Araujo, B., Faria-Campos, A. C., Chanock, S. J., et al. (2011). Phred-Phrap package to analyses tools: a pipeline to facilitate population genetics re-sequencing studies. Investig. Genet. 2:3. doi: 10.1186/2041-2223-2-3

Markowitz, V. M., Chen, I. M., Palaniappan, K., Chu, K., Szeto, E., Grechkin, Y., et al. (2012). IMG: the Integrated Microbial Genomes database and comparative analysis system. Nucleic Acids Res. 40, D115-D122. doi: $10.1093 /$ nar/gkr1044

Markowitz, V. M., Chen, I. M., Palaniappan, K., Chu, K., Szeto, E., Pillay, M., et al. (2014). IMG 4 version of the integrated microbial genomes comparative analysis system. Nucleic Acids Res. 42, D560-D567. doi: 10.1093/nar/gkt963

Markowitz, V. M., Korzeniewski, F., Palaniappan, K., Szeto, E., Werner, G., Padki, A., et al. (2006). The integrated microbial genomes (IMG) system. Nucleic Acids Res. 34, D344-D348. doi: 10.1093/nar/gkj024

Mead, D. A., Lucas, S., Copeland, A., Lapidus, A., Cheng, J. F., Bruce, D. C., et al. (2012). Complete Genome Sequence of Paenibacillus strain Y4.12MC10, a Novel Paenibacillus lautus strain Isolated from Obsidian Hot Spring in Yellowstone National Park. Stand. Genomic Sci. 6, 381-400. doi: 10.4056/sigs.2605792

Mead, D., Drinkwater, C., and Brumm, P. J. (2013). Genomic and enzymatic results show Bacillus cellulosilyticus uses a novel set of LPXTA carbohydrases to hydrolyze polysaccharides. PLOS ONE 8:e61131. doi: 10.1371/journal.pone.0061131

Merceron, R., Foucault, M., Haser, R., Mattes, R., Watzlawick, H., and Gouet, P. (2012). The molecular mechanism of thermostable alpha-galactosidases AgaA and AgaB explained by $\mathrm{x}$-ray crystallography and mutational studies. J. Biol. Chem. 287, 39642-39652. doi: 10.1074/jbc.M112.394114

Mok, S. C., Teh, A. H., Saito, J. A., Najimudin, N., and Alam, M. (2013). Crystal structure of a compact alpha-amylase from Geobacillus thermoleovorans. Enzyme Microb. Technol. 53, 46-54. doi: 10.1016/j.enzmictec.2013.03.009

Muhd Sakaff, M. K., Abdul Rahman, A. Y., Saito, J. A., Hou, S., and Alam, M. (2012). Complete genome sequence of the thermophilic bacterium Geobacillus thermoleovorans CCB_US3_UF5. J. Bacteriol. 194, 1239. doi: 10.1128/JB.06580-11

Narang, S., and Satyanarayana, T. (2001). Thermostable alpha-amylase production by an extreme thermophile Bacillus thermooleovorans. Lett. Appl. Microbiol. 32, 31-35. doi: 10.1046/j.1472-765x.2001.00849.x

Nasrollahi, S., Golalizadeh, L., Sajedi, R. H., Taghdir, M., Asghari, S. M., and Rassa, M. (2013). Substrate preference of a Geobacillus maltogenic amylase: a kinetic and thermodynamic analysis. Int. J. Biol. Macromol. 60, 1-9. doi: 10.1016/j.ijbiomac.2013.04.063

Nazina, T. N., Tourova, T. P., Poltaraus, A. B., Novikova, E. V., Grigoryan, A. A., Ivanova, A. E., et al. (2001). Taxonomic study of aerobic thermophilic bacilli: descriptions of Geobacillus subterraneus gen. nov., sp. nov. and Geobacillus uzenensis sp. nov. from petroleum reservoirs and transfer of Bacillus stearothermophilus, Bacillus thermocatenulatus, Bacillus thermoleovorans,
Bacillus kaustophilus, Bacillus thermodenitrificans to Geobacillus as the new combinations G. stearothermophilus, G. thermocatenulatus, G. thermoleovorans, G. kaustophilus, G. thermoglucosidasius and G., thermodenitrificans. Int. J. Syst. Evol. Microbiol. 51, 433-446. doi: 10.1099/ 00207713-51-2-433

Nishiya, Y., and Imanaka, T. (1990). Cloning and nucleotide sequences of the Bacillus stearothermophilus neutral protease gene and its transcriptional activator gene. J. Bacteriol. 172, 4861-4869.

Pati, A., Ivanova, N. N., Mikhailova, N., Ovchinnikova, G., Hooper, S. D., Lykidis, A., et al. (2010). GenePRIMP: a gene prediction improvement pipeline for prokaryotic genomes. Nat. Methods 7, 455-457. doi: 10.1038/nmeth.1457

Reizer, A., Deutscher, J., Saier, M. H. Jr., and Reizer, J. (1991). Analysis of the gluconate (gnt) operon of Bacillus subtilis. Mol. Microbiol. 5, 1081-1089. doi: 10.1111/j.1365-2958.1991.tb01880.x

Saha, B. C. (2003). Hemicellulose bioconversion. J. Ind. Microbiol. Biotechnol. 30, 279-291. doi: 10.1007/s10295-003-0049-x

Salama, R., Alalouf, O., Tabachnikov, O., Zolotnitsky, G., Shoham, G., and Shoham, Y. (2012). The abp gene in Geobacillus stearothermophilus T-6 encodes a GH27 beta-L-arabinopyranosidase. FEBS Lett. 586, 2436-2442. doi: 10.1016/j.febslet.2012.05.062

Sambrook, J., Fritsch, E. F., and Maniatis, T. (1989). Molecular Cloning: A Laboratory Manual. New York, NY: Cold Spring Harbor Laboratory Press.

Sen, S., and Oriel, P. (1989). Multiple amylase genes in two strains of Bacillus stearothermophilus. Gene 76, 137-144. doi: 10.1016/0378-1119(89) 90015-2

Shallom, D., Belakhov, V., Solomon, D., Shoham, G., Baasov, T., and Shoham, Y. (2002). Detailed kinetic analysis and identification of the nucleophile in alpha-L-arabinofuranosidase from Geobacillus stearothermophilus T-6, a family 51 glycoside hydrolase. J. Biol. Chem. 277, 43667-43673. doi: 10.1074/jbc.M208285200

Shintani, M., Ohtsubo, Y., Fukuda, K., Hosoyama, A., Ohji, S., Yamazoe, A., et al. (2014). Complete genome sequence of the Thermophilic Polychlorinated Biphenyl Degrader Geobacillus sp. Strain JF8 (NBRC 109937). Genome Announc. 2:e01213-13. doi: 10.1128/genomeA.01213-13

Shulami, S., Gat, O., Sonenshein, A. L., and Shoham, Y. (1999). The glucuronic acid utilization gene cluster from Bacillus stearothermophilus T-6. J. Bacteriol. 181, 3695-3704.

Shulami, S., Raz-Pasteur, A., Tabachnikov, O., Gilead-Gropper, S., Shner, I., and Shoham, Y. (2011). The L-Arabinan utilization system of Geobacillus stearothermophilus. J. Bacteriol. 193, 2838-2850. doi: 10.1128/JB.00222-11

Sinchaikul, S., Tyndall, J. D., Fothergill-Gilmore, L. A., Taylor, P., Phutrakul, S., Chen, S. T., et al. (2002). Expression, purification, crystallization and preliminary crystallographic analysis of a thermostable lipase from Bacillus stearothermophilus P1. Acta Crystallogr. Sect. D Biol. Crystallogr. 58(Pt 1), 182-185. doi: $10.1107 /$ S0907444901015803

Solomon, H. V., Tabachnikov, O., Feinberg, H., Govada, L., Chayen, N. E., Shoham, Y., et al. (2013). Crystallization and preliminary crystallographic analysis of GanB, a GH42 intracellular beta-galactosidase from Geobacillus stearothermophilus. Acta Crystallogr. Sect. F Struct. Biol. Cryst. Commun. 69(Pt 10), 1114-1119. doi: 10.1107/S1744309113023609

Solomon, V., Teplitsky, A., Shulami, S., Zolotnitsky, G., Shoham, Y., and Shoham, G. (2007). Structure-specificity relationships of an intracellular xylanase from Geobacillus stearothermophilus. Acta Crystallogr. Sect. D Biol. Crystallogr. $63(\mathrm{Pt}$ 8), 845-859. doi: 10.1107/S0907444907024845

Strauch, M. A. (1995). AbrB modulates expression and catabolite repression of a Bacillus subtilis ribose transport operon. J. Bacteriol. 177, 6727-6731.

Suen, G., Weimer, P. J., Stevenson, D. M., Aylward, F. O., Boyum, J., Deneke, J., et al. (2011). The complete genome sequence of Fibrobacter succinogenes S85 reveals a cellulolytic and metabolic specialist. PLOS ONE 6:e18814. doi: 10.1371/journal.pone.0018814

Takami, H., Nakasone, K., Takaki, Y., Maeno, G., Sasaki, R., Masui, N., et al. (2000). Complete genome sequence of the alkaliphilic bacterium Bacillus halodurans and genomic sequence comparison with Bacillus subtilis. Nucleic Acids Res. 28, 4317-4331. doi: 10.1093/nar/28.21.4317

Takami, H., Takaki, Y., Chee, G. J., Nishi, S., Shimamura, S., Suzuki, H., et al. (2004). Thermoadaptation trait revealed by the genome sequence of thermophilic Geobacillus kaustophilus. Nucleic Acids Res. 32, 6292-6303. doi: 10.1093/nar/gkh970 
Talbot, G., and Sygusch, J. (1990). Purification and characterization of thermostable beta-mannanase and alpha-galactosidase from Bacillus stearothermophilus. Appl. Environ. Microbiol. 56, 3505-3510.

Tamura, K., and Nei, M. (1993). Estimation of the number of nucleotide substitutions in the control region of mitochondrial DNA in humans and chimpanzees. Mol. Biol. Evol. 10, 512-526.

Tamura, K., Peterson, D., Peterson, N., Stecher, G., Nei, M., and Kumar, S. (2011). MEGA5: molecular evolutionary genetics analysis using maximum likelihood, evolutionary distance, and maximum parsimony methods. Mol. Biol. Evol. 28, 2731-2739. doi: 10.1093/molbev/msr121

Teplitsky, A., Mechaly, A., Stojanoff, V., Sainz, G., Golan, G., Feinberg, H., et al. (2004). Structure determination of the extracellular xylanase from Geobacillus stearothermophilus by selenomethionyl MAD phasing. Acta. Crystallogr. D Biol. Crystallogr. 60(Pt 5), 836-848. doi: 10.1107/S090744490 4004123

Tong, S., Porco, A., Isturiz, T., and Conway, T. (1996). Cloning and molecular genetic characterization of the Escherichia coli gntR, gntK, and gntU genes of GntI, the main system for gluconate metabolism. J. Bacteriol. 178, 3260-3269.

Tricarico, J. M., and Dawson, K. A. (2005). Influence of supplemental endoglucanase or xylanase on volatile fatty acid production from ruminant feed by ruminal in vitro cultures. Arch. Anim. Nutr. 59, 325-334. doi: 10.1080/17450390500247865

Valls, C., Gallardo, O., Vidal, T., Pastor, F. I., Diaz, P., and Roncero, M. B. (2010). New xylanases to obtain modified eucalypt fibres with highcellulose content. Bioresour. Technol. 101, 7439-7445. doi: 10.1016/j.biortech. 2010.04.085

Valls, C., and Roncero, M. B. (2009). Using both xylanase and laccase enzymes for pulp bleaching. Bioresour. Technol. 100, 2032-2039. doi: 10.1016/j.biortech.2008.10.009

Verma, D., and Satyanarayana, T. (2012). Cloning, expression and applicability of thermo-alkali-stable xylanase of Geobacillus thermoleovorans in generating xylooligosaccharides from agro-residues. Bioresour. Technol. 107, 333-338. doi: 10.1016/j.biortech.2011.12.055

Vieille, C., and Zeikus, G. J. (2001). Hyperthermophilic enzymes: sources, uses, and molecular mechanisms for thermostability. Microbiol. Mol. Biol. Rev. 65, 1-43. doi: 10.1128/MMBR.65.1.1-43.2001
Wiegand, S., Rabausch, U., Chow, J., Daniel, R., Streit, W. R., and Liesegang, H. (2013). Complete Genome Sequence of Geobacillus sp. Strain GHH01, a Thermophilic Lipase-Secreting Bacterium. Genome Announc. 1:e0009213. doi: 10.1128/genomeA.00092-13

Woodson, K., and Devine, K. M. (1994). Analysis of a ribose transport operon from Bacillus subtilis. Microbiology 140(Pt 8), 1829-1838. doi: 10.1099/13500872140-8-1829

Yao, N., Ren, Y., and Wang, W. (2013). Genome Sequence of a Thermophilic Bacillus, Geobacillus thermodenitrificans DSM465. Genome Announc. 1:e01046-13. doi: 10.1128/genomeA.01046-13

Yoshida, K., Sanbongi, A., Murakami, A., Suzuki, H., Takenaka, S., and Takami, H. (2012). Three inositol dehydrogenases involved in utilization and interconversion of inositol stereoisomers in a thermophile, Geobacillus kaustophilus HTA426. Microbiology 158(Pt 8), 1942-1952. doi: 10.1099/mic.0. 059980-0

Zeigler, D. R. (2005). Application of a recN sequence similarity analysis to the identification of species within the bacterial genus Geobacillus. Int. J. Syst. Evol. Microbiol. 55(Pt 3), 1171-1179. doi: 10.1099/ijs.0.63452-0

Zhao, Y., Caspers, M. P., Abee, T., Siezen, R. J., and Kort, R. (2012). Complete genome sequence of Geobacillus thermoglucosidans TNO-09.020, a thermophilic sporeformer associated with a dairy-processing environment. J. Bacteriol. 194, 4118. doi: 10.1128/JB.00318-12

Conflict of Interest Statement: The authors are employees and shareholders of C5-6 Technologies (WI, USA), a company that creates bio-based solutions to efficiently convert biomass into five and six carbon sugars. The authors have no other relevant affiliations or financial involvement with any organization or entity with a financial interest in or financial conflict with the subject matter or materials discussed in the manuscript apart from those disclosed. No writing assistance was utilized in the production of this manuscript.

Copyright (c) 2015 Brumm, De Maayer, Mead and Cowan. This is an open-access article distributed under the terms of the Creative Commons Attribution License (CC $B Y)$. The use, distribution or reproduction in other forums is permitted, provided the original author(s) or licensor are credited and that the original publication in this journal is cited, in accordance with accepted academic practice. No use, distribution or reproduction is permitted which does not comply with these terms. 